\title{
Interactions of brown marmorated stink bug, Colletotrichum acutatum and trap crops in organic tomato production
}

Robert James Voshell

Follow this and additional works at: https://researchrepository.wvu.edu/etd

\section{Recommended Citation}

Voshell, Robert James, "Interactions of brown marmorated stink bug, Colletotrichum acutatum and trap crops in organic tomato production" (2015). Graduate Theses, Dissertations, and Problem Reports. 6879. https://researchrepository.wvu.edu/etd/6879

This Thesis is protected by copyright and/or related rights. It has been brought to you by the The Research Repository @ WVU with permission from the rights-holder(s). You are free to use this Thesis in any way that is permitted by the copyright and related rights legislation that applies to your use. For other uses you must obtain permission from the rights-holder(s) directly, unless additional rights are indicated by a Creative Commons license in the record and/ or on the work itself. This Thesis has been accepted for inclusion in WVU Graduate Theses, Dissertations, and Problem Reports collection by an authorized administrator of The Research Repository @ WVU. For more information, please contact researchrepository@mail.wvu.edu. 


\title{
Interactions of brown marmorated stink bug, Colletotrichum acutatum and trap crops in organic tomato production
}

\author{
Robert James Voshell \\ Thesis submitted to the \\ Davis College of Agriculture Natural Resources and Design \\ at West Virginia University \\ in partial fulfillment of the requirements for the degree of \\ Master of Science in \\ Plant Pathology
}

James Kotcon, Ph.D., Chair

Yong-Lak Park, Ph.D.

Mahfuz Rahman, Ph.D.

Daniel Panaccione, Ph.D.

Division of Plant and Soil Science

Morgantown, West Virginia

2015

Keywords: Halyomorpha halys, Colletotrichum, Tomato anthracnose, Organic Copyright 2015 Robert James Voshell 


\section{ABSTRACT}

Colletotrichum spp. (Ascomycota) cause anthracnose of tomato fruits (Solanum lycopersicum). Halyomorpha halys, the Brown Marmorated Stink Bug (Hemiptera: Pentatomidae) is an invasive insect that injures tomato fruits with a piercing/sucking mouthpart.

To determine if $H$. halys feeding increases incidence of anthracnose on tomato fruit, five experiments were conducted. A 21-day transmission study was performed using detached fruits inside plastic containers in an incubator at $22^{\circ} \mathrm{C}$. Tomato fruits receiving stink bugs with Colletotrichum inoculum had significantly higher anthracnose incidence than fruit receiving Colletotrichum inoculum only. A treatment using infested stink bugs $(H$. halys was placed in a petri dish of sporulating C. acutatum for $24 \mathrm{~h}$ ) to assess transmission had significantly higher anthracnose incidence than the sterilized water control. In a stink bug wounding treatment $(H$. halys was placed in the container with tomato fruits for 7 days, removed, and Colletotrichum inoculum was sprayed), anthracnose incidence was significantly less than in a stink bugs + inoculum treatment at 10 and 17 days, but these treatments did not differ at 21 days. A whole plant study was performed inside insect rearing and observation cages for 17 days.

Anthracnose incidence on fruits of plants with stink bugs + inoculum was significantly greater than on all other treatments. Anthracnose incidence in the stink bug transmission and inoculum only treatments was significantly greater than with water controls or stink bug only treatments.

In a field experiment using whole plants, $0,1,3$, and $9 \mathrm{H}$. halys nymphs were added to mesh sleeves fitted around tomato fruit clusters for periods of 5 and 10 days. Number of stink bugs explains more of the variation $(P<0.001)$ in Colletotrichum incidence than days in sleeve $(P=0.1095)$. The two-way interaction between the days in sleeve and stink bug number was not significant $(P=0.6627)$. When averaged across days in sleeve, anthracnose incidence was higher in treatments with nine stink bugs than treatments with zero, one, or three stink bugs $(P<0.10)$.

Fungi were isolated from $\mathrm{H}$. halys fed on infected tomatoes in the lab. Stylets and legs were cultured on Yeast extract/sucrose agar to isolate colonies of $C$. acutatum. C. acutatum was recovered from either leg or stylet of $37.5 \%$ of insects feeding on infected fruit but not from control groups.

A large scale field study was conducted in 2013 to evaluate whether insect feeding scars on tomato fruits were correlated with presence of Colletotrichum spp. Trap crops of sunflower and corn were established around tomatoes to deter insect feeding on tomatoes. Visual sampling for $\mathrm{H}$. halys and other pentatomids was performed weekly. The field trials were repeated in 2014, however only sunflower was evaluated as a trap crop in 2014. H. halys populations were low in both seasons. No significant differences in $\mathrm{H}$. halys population densities were found between trap crop treatments in 2013. Feeding scars were positively correlated with anthracnose incidence $(R=0.2385)$ across both (sunflower and control) treatment groups in both seasons $(p<0.0001)$. This trend was consistent in sweet corn trap crop plots in 2013 as well $(p<0.018)$. These results support the hypothesis that $H$. halys contributes to the spread of anthracnose caused by $C$. acutatum in tomato by wounding and by phoretically carrying propagules from inoculum sources to susceptible hosts 


\section{DEDICATION}

I would like to dedicate this research effort to small farmers everywhere. May you prosper in providing essential nutrition to an increasingly interesting population of world citizens. 


\section{ACKNOWLEDGEMENTS}

I would first like to thank all of the more than human living entities that made this research possible. From the brown marmorated stink bug whom was placed in a strange land by global economies to the myriad array if soil organisms that supported my tomato plants from root-bound transplants to healthy robust primary producers, ecologies big and small made this research possible. May these efforts and others like them contribute to a more harmonized and nuanced approach to living within the complex and beautifully interconnected web of life we all depend upon for physiological, psychological, and spiritual sustenance.

Thanks to my advisor, Jim Kotcon for his time, patience, expertise, and insight in guiding me through the research process. Thanks to Yong-Lak Park for mentoring me on the finer points of stink bug rearing. Thanks to Dan Panaccione for guidance and expertise regarding mycological entities of all sorts. Thanks to Mafuz Rahman for guidance in diagnostics and experimental design.

Thanks to the Davis College statistician, Ida Holaskova, for her tireless efforts in guiding me through a large amount of tricky data analysis. Thanks to Sunghoon Baek for his gift of stink bug cultures and guidance in maintaining them. Thanks to Matt Kasson and Dylan Short for their work on determining the genetic identity of Colletotrichum samples. Thanks to Elaina Spahr, Audrey Geise, and Krissy Anderson for their contributions to the immense amount of field work involved in the project. Thanks to Anna Withrow for her support in canning tomato sauce and keeping me organized. Thanks to the Hastings Farm of Morgantown for their contribution of $\mathrm{H}$. halys individuals for experimentation. Thanks to Forever Greene House of Greene Co. PA for their donation of organic tomatoes for laboratory experiments.

This material is based upon work that is supported by the National Institute of Food and Agriculture, Organic Research and Extension Initiative, U.S. Department of Agriculture, under award number 2012-51300-20097. Thanks to the Davis College, especially the Division of Plant and Soil Sciences, as well as West Virginia University for providing me with the opportunity to contribute to the body of scientific knowledge in plant pathology.

I would like to thank all my family, especially my parents for continuing to support me through this windy road and my siblings for shaping me into the person I am today. 


\section{TABLE OF CONTENTS}

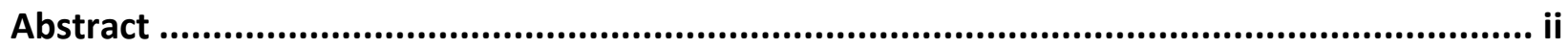

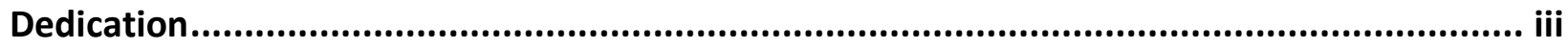

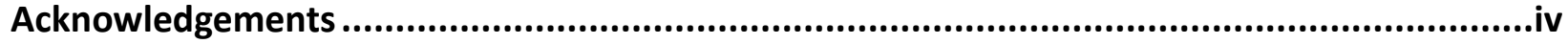

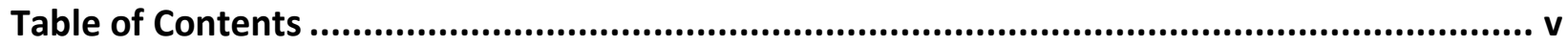

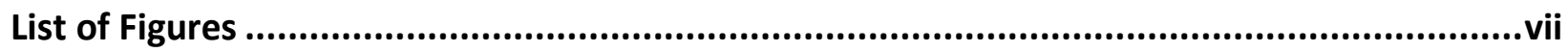

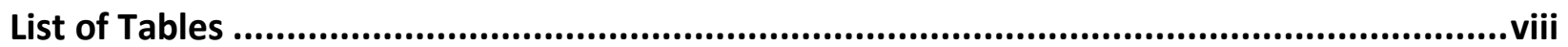

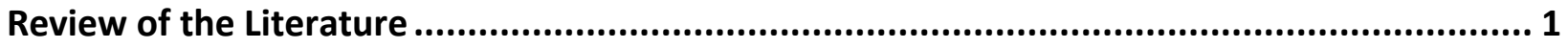

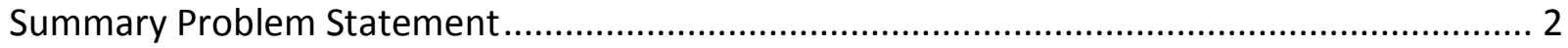

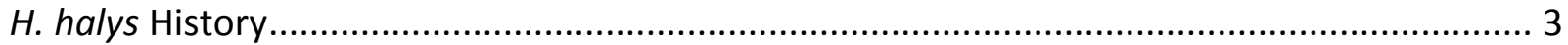

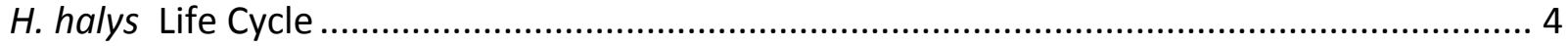

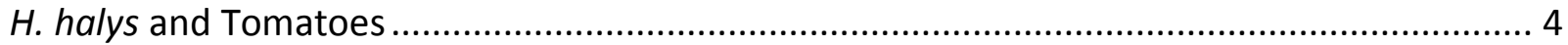

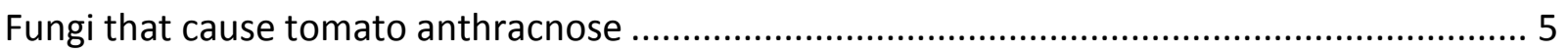

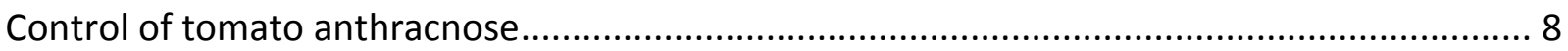

Other Heteroptera/fungal pathogen associations ........................................................... 9

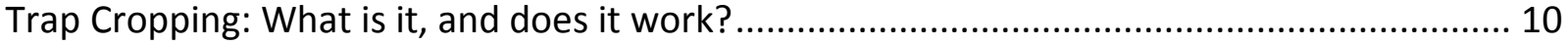

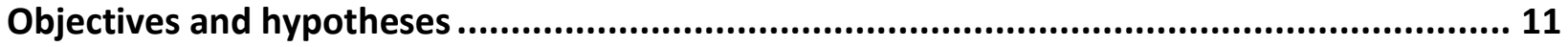

Chapter I Trap Cropping Effects on H. halys populations and Disease Incidence of Tomato ... 12

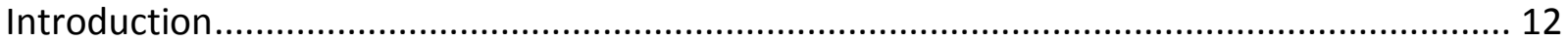

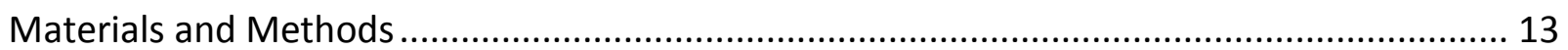

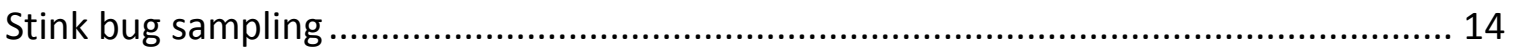

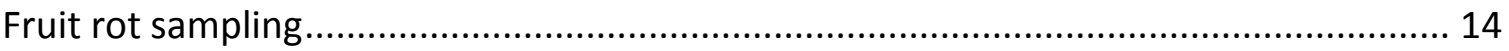

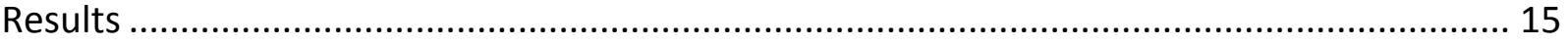

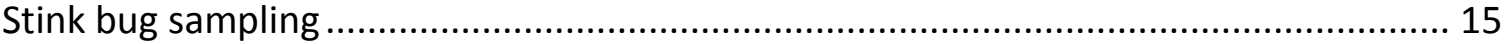

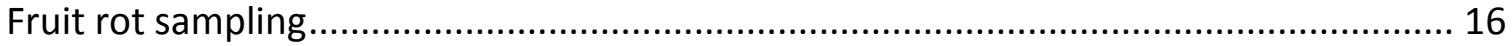

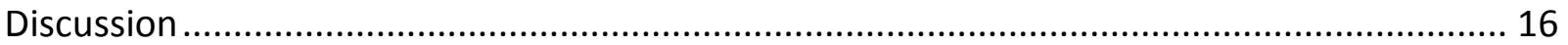

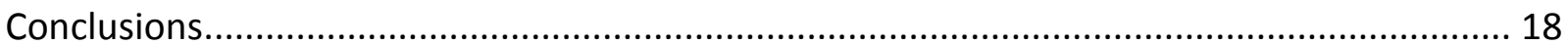

Chapter II Correlation of $\boldsymbol{H}$. halys feeding and anthracnose incidence and elucidation of mode

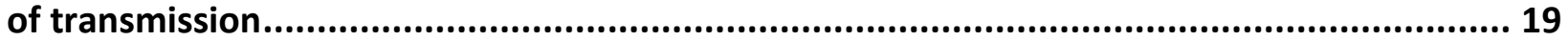

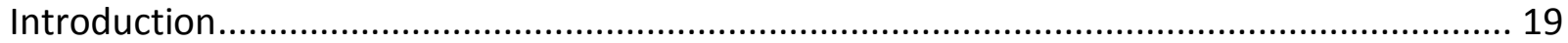

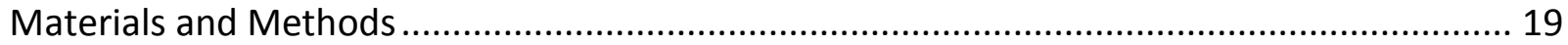


Insects 19

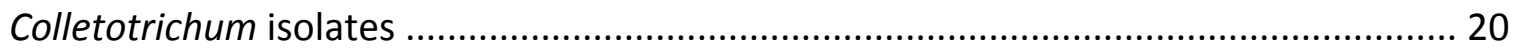

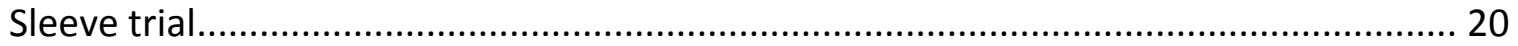

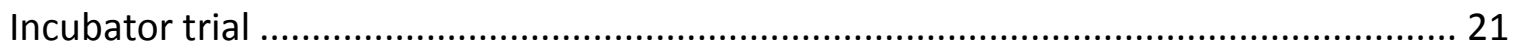

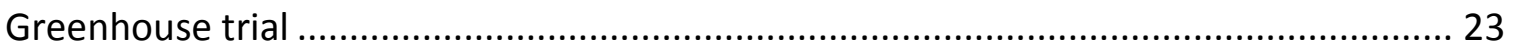

Fungal isolation from body parts of $H$. halys feeding on detached tomato fruit............ 25

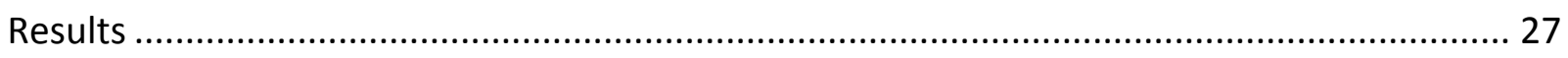

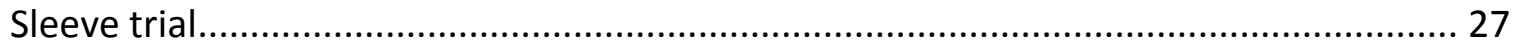

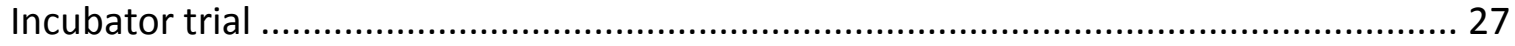

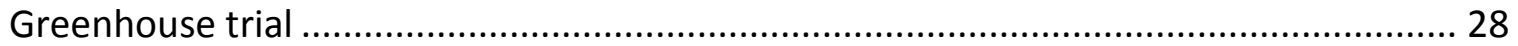

Fungal isolation from body parts of $H$. halys feeding on detached tomato fruit............ 28

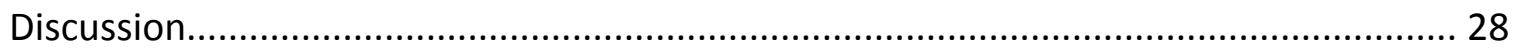

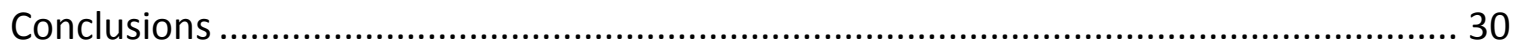

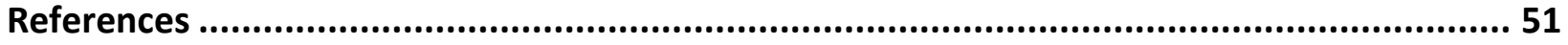

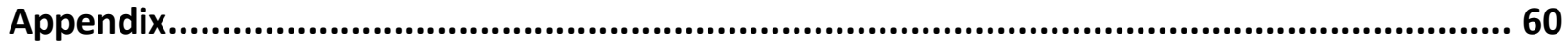




\section{LIST OF FIGURES}

\section{CHAPTER 1}

Figure 1.1 - Plot layout and sample points of trap crop plots established in 2013 and 2014

Figure 1.2 - Tomato fruits with varying stages of anthracnose ..................................... 32

Figure 1.3 - Tomato fruits with bacterial soft rot.............................................................. 33

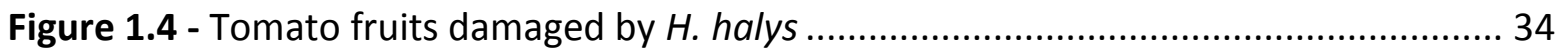

Figure 1.5 - Total average adult stink bugs per tomato plot in 2013 and 2014 ................. 35

Figure 1.6 - Total average stink bug nymphs per tomato plot in 2013 and 2014 .............. 36

Figure 1.7 -Total average stink bug nymphs per tomato plot in 2013 and 2014 with nymphs hatched from single egg mass removed from analysis.................................... 37

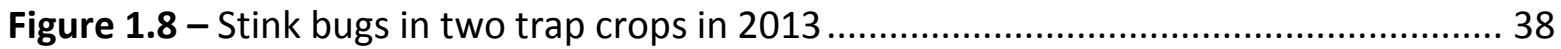

Figure 1.9 -Total average stink bugs found per tomato plot in 2013: a comparison of three trap crops

\section{CHAPTER 2}

Figure 2.1 - Anthracnose incidence averaged by stink bug number in the sleeve trial

Figure 2.2 - Pictures of tomatoes from different treatments in the incubator trial 41

Figure 2.3 - Anthracnose disease incidence in the incubator trial 42

Figure 2.4 - Total diseased fruit in the incubator trial ................................................ 43

Figure 2.5 - Anthracnose disease incidence in the greenhouse trial .............................. 44

Figure 2.6 - Percentage of total diseased fruit in the greenhouse trial ........................... 45

Figure 2.7 - Percentage of $H$. halys individuals that yielded viable $C$. acutatum cultures in the fungal isolation study 46

Figure 2.8 - Percentage of $H$. halys legs that yielded viable $C$. acutatum cultures ............ 47

Figure 2.9 - Percentage of $H$. hlays stylets that yielded viable $C$. acutatum cultures 48 


\section{LIST OF TABLES}

\section{CHAPTER 1}

Table 1.1 Non-parametric Spearman's correlation analysis of bacterial soft rot and stylet feeding scars on sunflower and control treatments across both seasons ............................ 49

Table 1.2 Monthly rainfall data for the 2013 and 2014 growing seasons ........................... 50

Table 1.3 Non-parametric correlation of disease parameters across treatments .................. 51 CHAPTER 2

Table 2.1 Two way analysis of variance of treatment effects on Colletotrichum incidence .... 52 
REVIEW OF LITERATURE 


\section{Summary Problem Statement}

In 1996 Halyomorpha halys (Hemiptera: Pentatomidae), a piercing and sucking insect from Asia, was unintentionally introduced to the eastern U.S. It has been a notable agricultural pest ever since with over 300 economic plant hosts, including tomato (Leskey et al. 2012a). It is known to feed on tomato fruits, Solanum lycopersicum, and grower observations suggest that feeding may lead to greater losses due to soft rot pathogens, especially from anthracnose caused by Colletotrichum spp. (Ascomycota). However, this relationship has not been verified through controlled experiments.

Due to the highly mobile nature of the insect and its high tolerance for insecticides, effective chemical control measures against $H$. halys are limited (Leskey et al 2012d), especially for organic producers (Lee et al. 2014b). Insecticides, such as organophosphates, are typically used to suppress $\mathrm{H}$. halys and other pentatomids, but are under increasing public scrutiny for their impacts on human and environmental health due to their activity as neurological inhibitors and endocrine disruptors (Koureas et al. 2012; Kamanyire 2004). Only one published study (Sargent et al. 2014) has examined the status of $H$. halys on S. lycopersicum, and it found that in home gardens using traps commercially marketed for catching stink bugs, stink bug numbers were greater on tomato than in gardens without traps. Therefore, it is important to evaluate non-chemical means of control such as habitat manipulation.

It is apparent that knowledge gaps exist regarding the behavior of $H$. halys in tomatobased agroecosystems as well as regarding its status as a vector of important soft-rot pathogens. The aims of the current research are to elucidate the relationship between $\mathrm{H}$. halys and soft rot pathogens of tomato, specifically Colletotrichum spp. that cause anthracnose and bacterial species that cause bacterial soft rot in laboratory, greenhouse, and field settings, as well as to evaluate the efficacy of sunflower to act as a trap crop for $H$. halys in tomato plots. 


\section{Introduction}

Invasive herbivorous insect species often present new challenges for agriculture. Since invasives evolve in a different ecological framework than the one to which they are introduced, rates of predation are low compared to their native range (Pedigo and Rice 2006). Those that are able to effectively compete for resources often induce high levels of economic damage in both organic and conventional vegetable production systems. Since organic growers are limited in the types of insecticide they are allowed to use, and insecticides frequently have non-target effects, there is a need for effective cultural and biological control methods to combat invasive herbivorous insects in an organic agricultural setting.

\section{H. halys History}

H. halys (Heteroptera: Pentatomidae), is an invasive insect in the U.S. It is a highly polyphagous plant pest, with over 300 economic plant hosts (Zhu et al. 2012; Hamilton 2009). Its native range includes areas in China, Korea, Japan, and Taiwan. It feeds through direct insertion of its stylet into host tissue. Adults can be identified by white bands near the tops of their antennae, and a black and white pattern on their membranous wings. They are also larger in size than native stink-bugs. The term 'marmorated' refers to the marbled pattern on their outer hard wings (Hamilton 2009).

H. halys was likely first introduced to the United States in 1996 in Allentown, PA (Hoebeke and Carter 2003). Researchers speculate that it came via bulk containers, shipped to ports either in Elizabeth, NJ, or in Philadelphia, PA (Hoebeke and Carter 2003). It was first noticed as an overwintering nuisance in homes. In 2001 Karen Bernhard of the Lehigh County Cooperative Extension Service sent specimens to the Entomology Lab at Cornell University. Richard Hoebeke identified the insects as Halyomorpha halys, now commonly known as brown marmorated stink bug (BMSB for short), or just "stink bugs" to many people who live in the areas of infestation (Hoebeke and Carter 2003).

Since its introduction in 1996, $H$. halys has been identified in nearly every non-arid state in the US. However, it is considered a severe agricultural pest only in MD, PA, WV, VA, and NJ (Zhu et al. 2012). Its population density has not yet reached levels in the western U.S. for it to be identified as a pest, however crops in California and other western states will likely be threatened (Zhu et al. 2012). It was introduced to Switzerland in 2004, and since then has become established in France, Italy, and Greece (Haye et al. 2014). Apples, peaches, pears, soybeans, sweet corn, and tomatoes are just some of the hosts on which damage has been reported.

The worst year of infestation in the Mid-Atlantic U.S. to date perhaps was 2010. The cost of damage to Mid-Atlantic apples alone was $\$ 37$ million. Some stone fruit growers lost more than $90 \%$ of their crop that same year (Leskey et al. 2012b). Estimates of damage to tomatoes were not performed, largely due to lack of knowledge of how $\mathrm{H}$. halys affects yield of tomato fruits.

H. halys is difficult to control for several reasons. First, it is highly mobile with many different plant hosts. Therefore, spraying an orchard or tomato field generally only kills insects on the crops at the time of application, often leaving significant populations within flying distance of the target crop unaffected (Leskey et al. 2012c). Stylet-feeding insects such as $H$. 
halys feed internal to the plant, and very little insecticide residue left on the surface of a plant is ingested while feeding. Walking on residues and cleaning of the body parts results in more insecticide exposure than that obtained through feeding. Several insecticide residues inhibit motion of the stink bug following exposure, and may therefore reduce damage to the plant. Leskey et al. (2012c) measured the initial efficacy and the change in efficacy 7 days after initial exposure to insecticide residues for 37 commonly used insecticides. It is advisable for growers using insecticides to consult this reference and to consider both initial and long term-efficacy of the insecticide to be used before making management decisions.

Second, $H$. halys generally requires a large dose of insecticide for mortality to occur, and has demonstrated the ability to recover from moribund condition following application of a number of commercially used insecticides, especially pyrethrins (Leskey et al. 2012d). Third, organic insecticides have lower efficacy against $H$. halys than those available to conventional growers. OMRI-approved materials with high efficacy in lab trials include bifenthrin, fenpropathrin, permethrin (three pyrethroids) and spinosad, however mortality often takes 4-5 days to occur (Leskey et al. 2012d; Lee et al. 2014b). Additionally, Spined Soldier Bug (Podisus maculventris), an important beneficial insect and predator of $H$. halys is more sensitive to these and other insecticide residues than $H$. halys (Lee et al. 2013b).

\section{H. halys Life Cycle}

H. halys overwinters as an adult in dry manmade structures, standing dead trees, or cliffs. (Lee et al. 2014; Leskey et al. 2012a). However, the largest numbers of overwintering $H$. halys are found in man-made structures (Lee et al. 2014a). In the spring, as photoperiod and temperature increase, $H$. halys leave their overwintering site, and fly out in search of food. Wiman et al. (2015) have shown that they may fly up to $75.12 \mathrm{~km}$ in a $24-\mathrm{h}$ period, although this is uncommon. Flight frequency, distance per flight, and sum flight distance were found to be significantly greater in freshly overwintered $H$. halys in laboratory trials. This is believed to coincide with greater food scarcity (Wiman et al. 2015).

Before mating, females feed for about 2 weeks, however this time period is variable and temperature dependent. Approximately 2 weeks after mating, females lay masses of 20-35 eggs on the undersides of leaves. Eggs hatch in 3-5 days. First instar nymphs are non-feeding (they do require water however) and are black, red, and white in color. Survivorship of $H$. halys nymphs and their subsequent progeny is highly dependent upon the presence of the gut symbiont Pantoea agglomerans (Taylor et al. 2014). There are five nymphal instars, and it takes an average of 42 days to complete their life cycle at $25^{\circ} \mathrm{C}$. Nymphal stages lack wings, and generally feed less than adults. Adults have a longer stylet and are highly mobile and highly polyphagous. Nielsen and Hamilton (2009) demonstrated univoltine behavior in Eastern Pennsylvania. However, Leskey et al. (2012c) found $H$. halys easily completed two generations in a season using semi-field cages at the Appalachian Fruit Research Station in Kearneysville, WV. As days get shorter and temperatures drop, the insects undergo diapause, and aggregate in overwintering sites.

\section{H. halys and Tomatoes}

Few studies concerning $\mathrm{H}$. halys' impact on the tomato (Solanum lycopersicum) industry have been conducted. Although it is well established that pentatomid insects damage tomato fruits, Sargent et al. (2014) is the only published research on the interaction of $H$. halys and $S$. 
lycopersicum to date. They performed a 32-participant home gardener study to assess the efficacy of pheromone-baited traps marketed for $\mathrm{H}$. halys control in gardens in summer 2012. The study revealed that the number of $H$. halys present on tomatoes was significantly greater in plots with pheromone-baited traps than in controls. However, no assessment of damage to fruits was made, nor was any effort made to quantify incidence of tomato fruit rot pathogens (Sargent et al. 2014).

Additionally, researchers at the University of Maryland College Park conducted an entomological survey of pentatomids in a three-farm trial in 2011. They found a consistently low number of adults $\left(<0.5 / \mathrm{m}^{2}\right)$ and few nymphs in trellised tomato plots sampled from early July to mid-September. Native green and brown stink bugs made up $85 \%$ of all stink bugs detected, however researchers speculate that $H$. halys may move in and out of tomato plots in a diurnal pattern. If true, this would make it difficult to quantify the number of $H$. halys that actually visit a field in a 24-hour period. Feeding scar incidence of 32-48\% ranged well beyond what was expected, given the number of stink bugs counted during sampling (Dively et al. 2012 unpublished data). These findings are consistent with the observations of researchers at the WVU Organic Farm in the 2011 and 2012 growing seasons. These observations suggest that, either the current methods to quantify $H$. halys in tomato fields underestimate the actual population density, or that a very few $\mathrm{H}$. halys can feed on and damage multiple tomato fruits. In either case, low $\mathrm{H}$. halys counts may be associated with a high incidence of feeding scars.

Anecdotal evidence from both researchers and growers indicate that yield loss in tomato production due to rot pathogens is higher when there is a large infestation of $H$. halys. However, no pathology studies have attempted to draw a correlation between $H$. halys feeding and prevalence of rot pathogens on harvested fruits.

\section{Fungi that cause tomato anthracnose}

Tomato fruits are susceptible to a wide range of rots caused by fungi and bacteria (Agrios 1997), however anthracnose caused by Colletotrichum spp. is considered to be the primary disease responsible for rot in tomato production (Gutierrez et al. 2006). Without management of anthracnose, yield loss up to $70 \%$ can occur when conditions are conducive to disease (Byrne et al. 1998).

\section{Symptomatology}

Anthracnose lesions are not typically visible until the fruit is ripe or over-ripe. On red fruits, lesions are dark, sunken, and grow outward in concentric circles. Setae may become visible as black or brown dots on the inner portion of the lesion, and turn more of the fruit black as the lesion develops. Under high humidity acervuli containing millions of conidia are visible in slimy salmon-colored droplets (Agrios 1997). Colletotrichum spp. overwinter in the soil, on tomato seed, on infested tomato debris, and are fairly ubiquitous in the environment (Dillard and Cobb 1998; Cannon et al. 2012).

\section{Colletotrichum coccodes s.l. and others: Understanding diversity of anthracnose-causing fungi}

Until recently, Colletotrichum coccodes was considered to be the sole causal agent of tomato anthracnose (Sanogo 2003; Dillard and Cobb 1998; Dillard 1989 a, b; Costa et al. 2006; Aqeel et al. 2008; Minuto et al. 2008; Nitzan et al. 2008; Ben-Daniel et al. 2009). This is likely due to a combination of morphological ambiguity and assumption of host specificity. In the 
past, identification of Colletotrichum spp. was performed using morpho-taxonomic criteria (Tu and Poysa 1997). These included host, shape and size of conidia, morphology, size of appressorium and setae, and response to temperature on PDA media. However, both morphology and phenotype are known to vary under environmental conditions, and modern phylogenetic study has brought the understanding that these features are not reliable for species diagnosis in the Colletotrichum genus (Cannon et al. 2012).

In addition to $C$. coccodes, $C$. acutatum, $C$. dematium, and, $C$. truncatum can cause tomato anthracnose as well ( $C$. truncatum has only been reported as causing tomato anthracnose in China) (Gutierrez et al. 2006; Jelev et al. 2008; Vichova et al. 2012).

The multiple Colletotrichum species pathogenic to tomatoes bear sufficiently close resemblance to each other that they cannot be properly distinguished except through molecular methods (Ariyawansa et al. 2014). Understanding possible differences in pathogenicity and lifestyles in species and races of Colletotrichum is necessary to develop and implement disease control strategies (Hyde et al. 2009). However, only a few papers on tomato anthracnose confirmed the genetic identity of the organism used (Gutierrez et al. 2006; Jelev et al. 2008; Vichova et al. 2012; and Diao et al. 2014). Most earlier studies did not (Dillard 1989; Sanogo et al. 2003; Costa et al. 2006; Aqeel et al. 2008; Minuto et al. 2008; Nitzan et al. 2008; Ben-Daniel et al. 2009). Modern molecular analysis reveals that any one of the four thus-far known causal agents of tomato anthracnose may have been the subject of earlier studies. Therefore, Colletotrichum coccodes sensu latu, or $C$. coccodes s.l. will be used to refer to the pathogen in studies that did not use modern phylogenetics to identify the causal agent of tomato anthracnose and assumed the pathogen to be Colletotrichum coccodes.

Growth parameters of $C$. coccodes s.l. were determined by Helene R. Dillard at Cornell University in the late 1980s and 1990s (Dillard 1986; Dillard 1988a, b; Dillard and Cobb 1998). She and her colleagues found the optimal growth temperature range to be $24^{\circ} \mathrm{C}$ to $30^{\circ} \mathrm{C}$, with little to no growth occurring below $10^{\circ} \mathrm{C}$ or above $31^{\circ} \mathrm{C}$ (Dillard $1988 \mathrm{a}$, b). Optimal germination of conidia occurred at $22^{\circ} \mathrm{C}$, whereas $28^{\circ} \mathrm{C}$ was the optimal germination temperature for sclerotia, which is logical as later germination of sclerotia would cause the organism to avoid late frosts (Dillard 1988b).

Infection of healthy fruit did not occur with 5 or fewer hours of free moisture, but occurred readily with 10 hours (Dillard 1988a). Germination of conidia was found to be the greatest at $28^{\circ} \mathrm{C}$ with a significant decrease at $31^{\circ} \mathrm{C}$ (Dillard 1998a). Optimal pH for conidial germination was between 5 and 7 , with 78.2, 84.8, and 65.6\% germination rates occurring at $\mathrm{pH}^{\prime} \mathrm{s} 5,6$, and 7 respectively. Little germination or growth occurred at $\mathrm{pH} 8$ and above, or $\mathrm{pH} 4$ and below (Dillard 1988b). Disease severity was shown to increase as inoculum density increased from $10^{1}$ to $10^{6}$ conidia/mL.

Interestingly, lesions per fruit, and lesion diameter were shown to significantly increase when tomatoes were punctured with a hypodermic needle containing spores of $C$. coccodes s.l. versus spray inoculation of unwounded fruits (Dillard 1988a).

Since phylogenetics has made it possible to distinguish among different species within the complex, only some of the above mentioned parameters have been measured for the other isolates of Colletotrichum spp. that cause tomato anthracnose. The optimal temperature for growth of a Chinese isolate of $C$. truncatum in culture is $25-30^{\circ} \mathrm{C}$ (Diao et al. 2014), whereas Dillard's isolate of $C$. coccodes had an optimal temp of $24-28^{\circ} \mathrm{C}$. Optimal cultural growth 
temperatures have not been documented for $C$. acuctatum or $C$. dematium isolates that cause tomato anthracnose (Vichova et al. 2012; Jelev et al. 2008, Gutierrez et al. 2006). However, C. acutatum isolates from tomatoes were successfully cultured at $25^{\circ} \mathrm{C}$ (Vichova et al. 2012; Jelev et al. 2008); and both C. dematium and C. acutatum were successfully cultured at $28^{\circ} \mathrm{C}$ (Gutierrez et al. 2006). Based on these studies, it is unlikely that significant differences in optimal temperature range exist among species within the genus, however this hypothesis has not been tested. Differences in the effect of wetness period, inoculum density, $\mathrm{pH}$, and osmotic potential among species have not been tested, nor have differences in overwintering capacity.

Two studies have compared aggressiveness among different isolates or species of Colletotrichum. Gutierrez et al. (2006) compared aggressiveness among 187 isolates of $C$. coccodes, $C$. acutatum, and $C$. dematium, (species were classified using restriction fragment length polymorphism analysis, and identified by internal transcribed spacer sequence analysis), and found no significant differences in lesion diameter at 3 and 7 days of incubation.

Ben-Daniel et al. (2009) compared aggressiveness on tomato among 12 strains of $C$. coccodes s.l. Four were from tomato, and eight were from potato. Ten $\mu \mathrm{L}$ of conidial suspension were injected in the stem scar of a green tomato fruit $1 \mathrm{~cm}$ deep. Fruits were cut open and lesion diameter and mass was measured 7 days post inoculation. No phylogenetic analysis was performed, rather, C. coccodes s.l. was identified using symptomatology and spore morphology. There were statistically significant differences in aggressiveness among several isolates, however these differences did not depend on host source. All strains, regardless of host source, were able to cause disease on both tomato and potato. Neither host species produced consistently more aggressive strains than the other. The most and least aggressive isolates were both from tomato. These results indicate that Colletotrichum spp. which cause anthracnose are ubiquitous in the agroecosystem and readily move between hosts.

\section{Distribution and Fungicide Sensitivity of Fungal Pathogens Causing Anthracnose-like Lesions on Tomatoes Grown in Ohio (Gutierrez et al. 2006)}

As mentioned above, studies using molecular methods to characterize causal agents of tomato anthracnose are few in number. Most that do so are simple first reports of a particular Colletotrichum species causing tomato anthracnose in a particular country (Diao et al. 2014; Vichova et al. 2012; Jelev et al. 2008).

Only one study (Gutierrez et al. 2006), attempted to survey anthracnose-like lesions from tomatoes over a broad area to determine which species are more commonly responsible for the disease. They isolated tomato anthracnose from 16 fields in seven Ohio counties with a large amount of tomato production. PCR was used to amplify the ITS-1 and ITS-2 regions of DNA from fungi cultured from fruits exhibiting anthracnose-like symptoms. Sequence analysis revealed that $30 \%$ of the 187 isolates from anthracnose-like lesions were from nonColletotrichum species. Of the remaining $70 \% ; 25 \%$ of isolates were Colletotrichum acutatum, $25 \%$ were $C$. dematium, and $50 \%$ were $C$. coccodes. All isolates were able to cause disease using infested broom straw as a wounding agent on ripe, excised tomato fruit.

Initially, Alternaria and Fusarium were found to mimic the early stages of anthracnose. Symptoms differ in latter stages, although they continue to cause degenerative decay that eliminates market value of the fruit. Prior to the study, Alternaria was not reported as a major 
fruit rot pathogen in Ohio, however in California it is considered the most devastating fruit rot pathogen (Morris et al. 2000).

\section{Control of tomato anthracnose}

Inoculum of Colletotrichum coccodes s.l. is capable of surviving many years in the soil as was demonstrated in a long-term study by Dillard and Cobb (1998). In silt-loam soil, 0, 90, and $88 \%$ of sclerotia remained viable after 8 years in soil pouches at 0,10 , and 20 -cm soil depths respectively. Survival of sclerotia was longer and more consistent when they were free in the soil versus associated with plant tissue. These results indicate that 8 years of rotation will not significantly reduce levels of infective inoculum. However, rotation is still advisable, as continued Solanaceous plantings in the same field will result in a buildup of inoculum.

\section{Organic control}

Organically approved control of Colletotrichum spp. is limited to cultural control and fungicides on the OMRI list of approved materials (OMRI.org). Mulching is recommended, as it aids in preventing splash of inoculum of Colletotrichum and other tomato pathogens from the soil to the fruit and stem (Agrios 1997). Hot water treatment of seed ( $122^{\circ} \mathrm{F}$ for $25 \mathrm{~min}$ ) is also recommended in addition to purchase of certified seed, however germination and vigor may be reduced if done incorrectly (Caldwell et al. 2013). Drip irrigation and trellising are also recommended as these practices reduce the fruit wetness period and minimize plant contact with the soil. Fruit wetness period is the most important condition in determining levels of infection (Dillard 1988a), therefore growers should employ cultural practices that decrease fruit wetness duration as much as possible.

Additionally, there is some evidence to suggest that addition of compost to the soil may reduce anthracnose disease severity. In a 2-year field study, Abbasi et al. (2002) showed that plots amended with 24-30 tons/acre of compost had significantly less anthracnose caused by $C$. coccodes than control plots when disease pressure was high, and no significant difference when disease pressure was low. Additionally, compost water extracts have shown promise in control of $C$. coccodes on peppers, and C. orbiculare on cucumber in recent greenhouse studies (Sang and Kim 2011). Currently there are no organically approved fungicides with demonstrated efficacy against $C$. coccodes. Copper hydroxide is the most widely used and effective organically approved fungicide, however in vitro studies demonstrated copper hydroxide to be ineffective at inhibiting growth of $C$. coccodes (Gutierrez et al. 2006; Dillard 1988).

\section{Conventional Control Methods}

Conventional growers able to rely on synthetic fungicides have more options for control of $C$. coccodes. Gutierrez et al. (2006) investigated the susceptibility of isolates of $C$. coccodes obtained from 16 tomato fields in seven counties of Ohio to different fungicides. Azoxystrobin, chlorothalonil, and mancozeb all significantly inhibited growth of $C$. coccodes $(\geq 47 \%)$ in vitro at concentrations expected to be found on tomato fruit given current application methods. Soil fumigation with dimethyl disulfide at 40 or $80 \mathrm{~g} \mathrm{~m}^{-2}$ and metham sodium at $192 \mathrm{gm}^{-2}$ were effective for control of root rot associated with C. coccodes s.l. in tomato (Garibaldi et al. 2008). While control of fruit rot was not evaluated, the study shows that fumigation, although more environmentally toxic, may be an effective option for reducing primary inoculum. 


\section{Other Heteroptera/Fungal Pathogen Associations}

It has long been known that insects are capable of introducing pathogens to plant hosts, with many important examples throughout the history of plant pathology (Agrios 1997). For example, Ophiostoma ulmi (the causal agent of Dutch elm disease), which devastated the elm population of America in the early to mid-1900s, formed a tight vector relationship with several species of elm bark beetle causing an epidemic.

The ability of piercing/sucking insects to transmit plant disease is closely linked to feeding mode and target tissue (Mitchell 2004). Heteropteran insects, (the suborder of Hemiptera to which stink bugs belong), have generally not been considered efficient vectors of plant pathogens (Carter 1973), and their economic importance as vectors is uncertain (Mitchell 2004).

Nevertheless, of the six superfamilies within Heteroptera associated with phytopathogenic bacteria, fungi, and trypanosomes, the association between pentatomids and fungi is the strongest with 43 documented associations (Mitchell 2004). Heteroptera have been associated with a variety of fungal diseases such as tree cankers, leaf spots, pod and boll rots, and grain and legume decay. The most studied of these are stigmatomycosis (associated with citrus, coffee, cotton, lima bean, pistachio, and soybean) and pecky rice (Mitchell 2004). Both involve fungal infection of the seed or embryo following direct feeding.

Eremothecium ashbyi and E. coryli (formerly Nematospora) are the causal agents of yeast spot disease in soybean and are transmitted by pentatomids (Daugherty 1967; Kimura et al. 2008a, b). Six American species of pentatomid (Daugherty 1967) and the four stink bug species found in Japan (Kimura et al. 2008a) vector soybean spot pathogens. Both E. ashbyi and E. coryli were found in the maxillary and mandibular stylet pouches of Riptortus pedestris. A mycelial mass of $E$. ashbyi developed in the stylet pouch one day after acquisition of ascospores, while a mass of $E$. coryli buds of irregular shape and size developed in the stylet. It should be noted, however that 26 of the 50 insects that fed on inoculated soybeans did not acquire ascospores of either yeast (Kimura et al. 2008b). The southern green stink bug, Nezara viridula was not only shown to transmit Nematospora coryli, an opportunistic pathogen of cotton boll, but also the bacterial cotton pathogens Pantoea agglomerans, $P$. ananatis, and Klebsiella pneumonia (Medrano et al. 2009). The western conifer seed bug, Leptoglossus occidentalis, was introduced to Italy in 1999, and has since been found to be associated with Diplodia pinea which has become an increasing threat to Italian conifers, especially Pinus pinea, the Italian Stone pine (Luchi et al. 2011).

Three studies mention members of Pentatomidae as being responsible for the transmission of Nematospora sp. (Currently Eremothecium) to tomato (Cullen and Zalom 2000; Hoffman et al 1987; Pease and Zalom 2010). However none mention an experiment that established this relationship.

Insect transmission is not ubiquitous, for example, brown stink bug, Euschistus servus (Hemiptera: Pentatomidae) was found to have no effect on smut infection percentage of maize in a four-year trial (Xinzhi et al. 2014). 


\section{Trap Cropping: What is it, and does it work?}

The human and environmental health impact of insecticides, such as the organophosphates traditionally used against pentatomids (Koureas et al. 2012; Kamanyire and Karalliedde 2004), are well-documented. Therefore, there is much interest in mitigating damage caused by difficult-to-kill insects such as Halyomorpha halys through alternative approaches (Shelton and Badenes-Perez 2006). Trap cropping is a simple concept involving habitat manipulation of the agroecosystem. A plant stand is established for the purpose of attracting diverting, intercepting, or retaining targeted insects or the pathogens they vector in hopes of protecting the cash crop attacked by the pest insect (Shelton and Badenes-Perez 2006).

Trap-cropping was a common and reportedly effective defense against diamondback moth in cruciferous plantings in the era before insecticides (Talekar and Shelton 1993). The use of marigold, Tagetes sp., as a trap for the fruit borer Helicoverpa armigera (Hubner) in tomato, is becoming an increasingly prevalent practice in India. There it is the number one insect pest of tomato, which is an important staple of the contemporary Indian diet. Single rows of Tagetes sp. are planted every 14 rows of tomato and should be 15 days older than the tomato plants to provide an oviposition site for H. armigera (Dhandapani et al. 2003).

In contemporary modern agriculture, two primary types of trap cropping are employed. The first, "conventional trap cropping", refers to a block of trap crops planted next to a block of a higher value crop for the purposes of trapping (Shelton and Badenes-Perez 2006).

Conventional trap cropping has been successfully implemented on commercials scales in suppression of lygus bugs on cotton fields by use of alfalfa as a trap (Godfrey and Leigh 1994; Stern 1969), and for suppression of squash bug and cucumber beetles in several cucurbitaceous crops by use of more attractive varieties as a trap (Pair 1997). Additionally, mustard trap crops were shown to significantly reduce damage by harlequin bug, Murgantia histrionica, to collard greens (Wallingford et al. 2013). The second type, perimeter trap cropping, is the planting of a trap crop as a border around a main crop. This type of trap cropping has been successfully employed in the suppression of the pepper seed maggot Zonosemata electa, in bell pepper plots (Boucher et al. 2003). 


\section{Objectives}

1. Determine whether sunflower and/or corn trap crops affect density of H. halys or disease incidence of anthracnose and bacterial soft rot of tomato fruit.

2. Assess the effects of differing populations of $H$. halys on losses due to fruit rot in organic tomato production systems

3. Determine what correlation if any exists between feeding scars characteristic of those made by $\mathrm{H}$. halys or other pentatomids and incidence of anthracnose and bacterial soft rot of tomato fruit.

4. Assess the transmission capabilities of $H$. halys with respect to Colletotrichum spp.

5. Assess the ability of $H$. halys to phoretically carry infective spores of Colletotrichum acutatum

6. Assess the effects of $H$. halys wounds on tomato fruits with respect to pathogen susceptibility

\section{Hypotheses}

1. H. halys density and anthracnose incidence will be lower in tomato in plots with sunflower or corn as a trap crop than in plots without a trap crop

2. Larger populations of $H$. halys will lead to significantly higher rates of infection by soft rot pathogens on tomato fruit.

3. Feeding scars characteristic of those made by $\mathrm{H}$. halys and other stylet feeding insects will be significantly correlated with incidence of anthracnose and bacterial soft rot of tomato.

4. H. halys transmits Colletotrichum spp. from infected to uninfected tomato fruit

5. H. halys is capable of carrying infective spores of Colletotrichum spp. phoretically

6. Wounding of tomato fruit by $\mathrm{H}$. halys will lead to greater susceptibility of tomato fruit to fruit rot pathogens such as anthracnose caused by Colletotrichum spp. 


\section{Chapter I. Trap Cropping Effects on H. halys Populations and Disease Incidence of Tomato}

When referring to insects in this chapter the term "stink bugs" will refer to total pentatomid species present in a particular ecological regime. The term includes the brown marmorated stink bug, Halyomorpha halys, the green stink bug, Chinavia hilaris, the southern green stink bug, Nezara virdula, and the brown stink bug Euschistus servus. The term "other stink bugs" refers to all species of pentatomid other than $H$. halys.

\section{Introduction}

H. halys was likely first introduced to the United States in 1996 in Allentown, PA (Hoebeke and Carter 2003). Researchers speculate that it came via bulk containers, shipped to ports either in Elizabeth, NJ, or in Philadelphia, PA (Hoebeke and Carter 2003). It was first noticed as an overwintering nuisance in homes. In 2001 Karen Bernhard of the Lehigh County Cooperative Extension Service sent specimens to the Entomology Lab at Cornell University. Richard Hoebeke identified the insects as Halyomorpha halys, now commonly known as brown marmorated stink bug (BMSB).

Since its introduction in 1996, $H$. halys has been identified in nearly every non-arid state in the US. However, it is considered a severe agricultural pest only in MD, PA, WV, VA, and NJ (Zhu et al. 2012). Its population density has not yet reached levels in the western U.S. for it to be identified as a pest, however California agriculture will likely be threatened along with other western states (Zhu et al. 2012).

Although it is well established that pentatomid insects damage tomato fruits, at present, Sargent et al. (2014) is the only research publication found on the interaction of $H$. halys and $S$. lycopersicum in a field setting. Anecdotal evidence from both researchers and growers indicate that yield loss in tomato production due to rot pathogens is higher when there is a large infestation of $\mathrm{H}$. halys. However, no pathology studies have attempted to draw a correlation between $\mathrm{H}$. halys population density and prevalence of rot pathogens on harvested fruits.

$H$. halys is difficult to control for several reasons. First, it is highly mobile with many different plant hosts. Therefore, spraying an orchard or tomato field generally only kills insects on the crops at the time of application, often leaving significant populations within flying distance of the target crop unaffected (Leskey et al. 2012c). Stylet-feeding insects such as $H$. halys feed internal to the plant, and very little insecticide residue left on the surface of a plant is ingested while feeding. Walking on residues and cleaning of the body parts results in more insecticide exposure than that obtained through feeding. Several insecticide residues inhibit motion of the stink bug following exposure, and may therefore reduce damage to the plant. Leskey et al. (2012c) measured the initial efficacy and the change in efficacy 7 days after initial exposure to insecticide residues for 37 commonly used insecticides. It is advisable for growers using insecticides to consult this reference and to consider both initial and long term-efficacy of the insecticide to be used before making management decisions.

Second, $H$. halys generally requires a large dose of insecticide for mortality to occur, and has demonstrated the ability to recover from moribund condition following application of a number of commercially used insecticides, especially pyrethrins (Leskey et al. 2012d). Third, 
organic insecticides have lower efficacy against $H$. halys than those available to conventional growers. OMRI-approved materials with high efficacy in lab trials include bifenthrin, fenpropathrin, permethrin (three pyrethroids) and spinosad, however mortality often takes 4-5 days to occur (Leskey et al. 2012d; Lee et al. 2014b). Additionally, Spined Soldier Bug (Podisus maculventris), an important beneficial insect and predator of $H$. halys is more sensitive to these and other insecticide residues than $H$. halys (Lee et al. 2013b).

Organophosphates are typically used to suppress $H$. halys and other pentatomids, but are under increasing public scrutiny for their impacts on human and environmental health due to their activity as neurological inhibitors and endocrine disruptors (Koureas et al. 2012; Kamanyire 2004). Additionally, organic producers don't have these or other synthetic insecticides as an option.

No published studies have evaluated cultural control measures of $H$. halys in tomato production. Here, for the first time, $H$. halys populations in tomato fields with established trap crops of corn and sunflower were compared to tomato fields with a mowed border and no trap crop. This is also the first study that correlates feeding scars characteristic of $H$. halys with disease incidence in tomato fruit.

\section{Materials and Methods}

\section{Field Plot Layout and Treatment Design}

Field trials were conducted in the 2013 and 2014 growing seasons at the WVU Organic Research Farm to test the effectiveness of trap crops to modify $H$. halys populations within tomato plots. Six $30.5 \times 30.5-\mathrm{m}$ plots were established at locations at least $200 \mathrm{~m}$ apart in order to minimize plot-to-plot interference by $\mathrm{H}$. halys. In the center of each plot, eight tomato plants (the main crop) were spaced $1.2 \mathrm{~m}$ apart within each of eight rows, with $1.5 \mathrm{~m}$ between rows (Fig. 1.1). On May 1, 2013 tomatoes, Solanum lycopersicum cv. Washington Cherry were started from seed (Johnny's Selected Seeds Co. Fairfield, ME) in plug trays using 1:1:1 perlite: compost: peat moss and placed on a mist bed. At 14 days after seeding, seedlings were transplanted to 32 -cell flats (flats were $25 \times 50.5 \mathrm{~cm}$, individual cells were $4 \times 6 \times 5.5 \mathrm{~cm}$ ). Plants were transplanted to soil in field plots on June 5. In 2014, seeds were started on May 30, and were transplanted to soil on July 5 in order to better coincide with the population increase of $H$. halys that comes with its second generation in September. Plants were staked and tied individually. Drip irrigation tape was established, but not used, as rainfall was high enough that irrigation of the crop was unnecessary (Table 1.2). Straw mulch over a double layer of newsprint was employed to suppress weeds and maintain moisture levels in the soil. A trap crop perimeter consisting of three rows was established $3 \mathrm{~m}$ outside of the tomato plot. No other controls of insects or pathogens were implemented. Seeds were planted $15 \mathrm{~cm}$ apart within rows spaced $92 \mathrm{~cm}$ apart. The inner-most row was planted 1 week before tomatoes, with the second, and third (outer-most) row planted at 10-day intervals. In the remaining perimeter area, organic winter rye Secale cereale (variety not stated) was established 1 week following tomato transplanting. Rye was mowed three times throughout the growing season, maintaining a vegetative state. Two replicates of three treatments were established in the 2013 growing season: Treatment one was a control and consisted of a tomato main crop surrounded by a mowed-rye perimeter. Treatment two consisted of a tomato main crop and a sunflower (Helianthus annus cv. Sierra) 
trap crop with a rye perimeter. Treatment three consisted of a tomato main crop and a sweet corn (Zea maize cv. Luscious) trap crop with a rye perimeter. Treatment three was not repeated in 2014. Three replicates of treatments one and two were established in the 2014 growing season.

\section{Stinkbug sampling}

Sampling for $H$. halys and other stink bugs was performed once each week starting when tomatoes began to ripen, and continued until production declined. For Washington Cherry tomato plants (a determinant variety), this was a period of approximately 5 weeks. In 2013 sampling was performed 35 to 77 days after transplanting (DAT). In 2014 sampling was performed from 60 to 88 DAT. The first replication of each treatment was sampled beginning at $9 \mathrm{am}$; the second replication of each treatment was sampled beginning at $1 \mathrm{pm}$. Each plant was inspected for 30 seconds for the presence of stink bugs with special attention paid to fruit clusters, as this is the most common and important feeding site for $\mathrm{H}$. halys on tomato plants. The four center tomato plants and two plants in the middle edge of the outer row at each cardinal direction were sampled (Fig. 1.1). Two trap crop plants per row on each side of the plot were sampled as well (Fig. 1.1).

\section{Fruit rot sampling}

The same tomato plants sampled for $H$. halys were used for Colletotrichum sampling. Ripe fruits were harvested weekly from each plant. A maximum of eight fruits per sample plant per week were incubated in the lab at room temperature $\left(23 \pm 2^{\circ} \mathrm{C}\right)$ for 7 days. On day seven, the fruits were visually evaluated and rated for the presence or absence of symptoms in several disease related categories. Categories included incidence of anthracnose, bacterial soft rot, black spotting, mold, stylet-feeding insect scars, cracking or splitting, and marketability. Anthracnose was identified by blackened lesions which formed outwardly expanding concentric water-soaked lesions (Fig. 1.2). Sporulating infections were scraped, and spores were confirmed as Colletotrichum spp. using Barnett and Hunter (1972). Bacterial soft rot was identified as fruits having a swollen, watery region, with no inherent discoloration associated with the lesion, although discoloration could be present (Fig. 1.3). Black spotting was used to describe fruits with black lesions exhibiting symptoms characteristic of other rot pathogens such as Bacterial spot, Fusarium spp. Rhizoctonia solani or Alternaria solani. These were described based on the

findings and descriptions of Gutierrez et al. (2006) and Agrios (1997). Stylet feeding insect scars was identified by characteristic cloud scars that form on tomato fruits after $H$. halys feeding (Fig. 1.4).

Fruits were given a marketability score based on several characteristics. While the United States Standard for Grades of Fresh Tomatoes could have been used as a guideline, tolerances are based upon grading a large quantity of tomatoes as a whole, and do not include standards for the marketability of an individual tomato fruit (USDA 1997). The USDA standard allows for up to $5 \%$ of fruits in a load affected by some kind of soft rot pathogen. Therefore, a rating system was designed by the researcher for use with individual fruits as follows: Since anthracnose lesions grow slowly initially, fruits with lesions $<2 \mathrm{~mm}$ were considered marketable, if larger it was rated as unmarketable. If five or more feeding scars were present, the fruit was 
considered unmarketable. If soft spots were present, the fruit was considered unmarketable. If black spotting covered $>30 \%$ of the fruit surface it was considered unmarketable.

\section{Data analysis}

Data were analyzed using JMP and SAS software (JMP ${ }^{\circledR}$, Version Pro 11, SAS Institute Inc., Cary, NC, Copyright (C2013; SAS ${ }^{\circledR}$, Version 9.3, SAS Institute Inc., Cary, NC, Copyright (C)2002-2010). For fruit rot sampling data, tomatoes sampled from plants on the perimeter of plots were averaged and used as experimental units. Tomatoes sampled in the center were averaged and used as a separate experimental unit. Due to low stink bug numbers, the whole plot was used as the experimental unit for the stink bug sampling data. Those variables with a high degree of normality (>88\% normally distributed) were analyzed using parametric methods (Shapiro-Wilk W test was performed to compare means by treatment and harvest). These included Colletotrichum Incidence, feeding scar incidence and soft rot incidence. Remaining variables had non-normally distributed data ( $<85 \%$ normally distributed) and were analyzed using nonparametric methods (Kruskall Wallis one-way analysis). To determine if a correlation existed between insect feeding scars and Colletotrichum incidence, a non-parametric Spearmans correlation analysis was performed using the tomato fruit as the experimental unit. This analysis was conducted on individual treatments and individual seasons as well as across all fruits from all seasons. Stink bug sampling data were analyzed in JMP (SAS institute) using Kruskall-Wallace one-way analysis for comparison of means. Treatment effects were determined for total $H$. halys, adult $H$. halys, $H$. halys nymphs, total other stink bugs, adult other stink bugs, nymph other stink bugs, total stink bugs, total adult stink bugs, and total stinkbug nymphs for 2013, 2014, and 2013 and 2014 combined in tomato plots and trap crops separately.

\section{Results}

Total stink bug numbers were low in both seasons; 87 stink bugs were observed in 2013 and 63 in 2014. Forty-four of the stink bugs observed in 2013 were from a single $H$. halys eggmass laid on the underside of a tomato leaf in a sunflower replicate, which hatched around 35 days after planting.

In 2013, the first $H$. halys individual was observed 35 days after planting (July 10) on a tomato plant in a control plot. In 2014 no $\mathrm{H}$. halys were observed in experimental plots until 67 days after transplanting (Sept. 3). However, two common green stink bugs (Nezara viridula) were observed on a sunflower plant and a tomato plant in a control plot at 60 days after transplanting (Aug 27). Overall counts of $H$. halys were low in both seasons.

Both growing seasons were wetter than average (Table 1.1). Incidence of powdery mildew was 100\% in 2013 (Little powdery mildew was seen in 2014 and no data were recorded on it). In between the second and third week of tomato harvest in 2013 (8/9 and 8/16), all tomatoes in one corn replicate plot were consumed by deer. This eliminated the last 2 weeks of stink bug sampling data.

\section{Stink bug Population Dynamics}

For the sake of brevity, separate analyses for $\mathrm{H}$. halys and other stink bugs are not included, only the combined total stink bug data are presented in the figures and discussed 
below. $H$. halys made up the majority of stink bugs observed, and the general trends observed with $H$. halys were also true when other stink bugs were added to the analysis. Where $H$. halys made up $>50 \%$ of stink bugs sampled it is noted in the figure caption or text.

There were significantly fewer adult total stink bugs in tomato plots with a sunflower trap crop than in control plots when both years were analyzed together (Fig.1.5 P=0.0468). When analyzed separately, fewer adult total stink bugs were found on tomatoes in trap crop plots than in control plots in $2013(P=0.06)$ but the trend was not significant in $2014(P=0.37)$ (data not shown).

The trend of fewer total stink bugs on tomatoes with sunflower was reversed but not significant for nymphs in 2013 ( $P=0.51$, data not shown), in 2014( $P=0.35$ data not shown) and both years combined (Fig. 1.6). A single $H$. halys egg mass laid on the leaf of a tomato plant selected for sampling in a sunflower plot in 2013 accounted for the majority of stink bugs of all species sampled in tomatoes that season. When the egg mass was removed from analysis (Fig. 1.7), nymphs were still more numerous on tomatoes with sunflower trap crops than controls, however differences were much smaller (Figs. 1.6 and 1.7).

More total stink bugs were found on sunflower plants than corn plants in 2013 (Fig. 1.8), however the difference was not significant. Means were 1.35 and 0.67 total stink bugs per 12 $\mathrm{m}^{2}$ per sampling period in sunflower and corn respectively. There was an increase in total stink bugs found in sunflower trap crops in 2014 to 3.07 insects per $12 \mathrm{~m}^{2}$ per sampling period. One hundred percent of stink bugs observed on sunflower in 2013 were $H$. halys; this fell to ninetyeight in 2014. Eighty-eight percent of stink bugs observed on corn in 2013 were $\mathrm{H}$. halys.

In 2013, tomatoes with a corn trap crop had the lowest average count of total stink bugs overall (Fig. 1.9). Although it is unclear as to how it makes a difference, it should be noted that one of the corn replicates had two fewer weeks of sampling than all other plots that growing season. There were only 3 total stink bugs sampled in tomatoes total during these last two weeks. During the second to last week there were 18 stink bugs observed sunflower trap crops, and five stink bugs in corn trap crops, these numbers dropped to one and two respectively during the last week of observation.

\section{Fruit rot sampling}

Anthracnose incidence was high in both seasons; 52\% in 2013, and 35\% in 2014. Treatment effects on anthracnose incidence or incidence of stink bug injury were not statistically significant. Incidence of feeding scars was positively correlated with anthracnose incidence $(r=0.2385)$ when data were averaged across sunflower and control plots in both growing seasons $(\mathrm{P}<0.0001)$ (Table 1.3). This trend was consistent in sweet corn trap crop plots in 2013 as well $(P<0.018)$. Feeding scars were also positively correlated with soft rot $(r=0.0855)$ combined across sunflower and controls in both growing seasons $(p<0.0001)$ (Table 1.3). However the trend with soft rot was significant in weeks 4-6 of harvest, marginally significant in week 2 and not significant in weeks 1 and 3 (Table 1.1).

\section{Discussion}

This is the first study that has correlated stink bug feeding scars and tomato disease incidence in a field setting. While it is speculated that the majority of the feeding scars in this study came from $\mathrm{H}$. halys and its pentatomid relatives, the actual causal agents of injuries on 
tomatoes are unknown. Many phytophagous, stylet-feeding insects are capable of inducing scars similar to those caused by $\mathrm{H}$. halys. However, based on field observations it is unlikely that a significant portion of feeding scars came from non-pentatomid species, as no other known insect pest of tomato was observed in tomato fields other than tomato hornworm, Manduca quinquemaculata, which has chewing mouthparts and is likely incapable of injuring tomatoes in a similar manner to Pentatomids. Regardless of the source of the injury, it is positively correlated with anthracnose incidence $(r=0.2385)$ (Table 1.1). Because the trend remained significant consistently among all treatments across all weeks (data not shown), there is strong evidence for a positive association between the two.

Pentatomids are generally considered nocturnal (Cullen and Zalom 2000), and while this behavior has not been properly confirmed in $\mathrm{H}$. halys, anecdotal evidence suggests that their activity increases at night (Leskey and Hamilton 2010). Nocturnal feeding may help explain the high levels of injury over the growing season in spite of the fact that very few insects were observed on tomato plants during sampling times, which were during daylight hours. To investigate this possibility, twice in the 2013 season, at 70 and 77 days after planting, nocturnal observations were made to determine if $H$. halys counts on tomatoes and trap crops would vary from those made during the day. There were many $H$. halys individuals found on both trap crops and very few if any were found on tomatoes during daytime sampling on those dates. It was observed that nocturnal counts were similar or identical to daytime counts, and no evidence for significant host-switching behavior was observed on either of these two occasions.

While correlation between feeding scars and bacterial soft rot was positive and significant, the trend was very inconsistent (Table 1.1). The evidence for a positive association of feeding scars and bacterial soft rot is tenuous, however the probability of an association is plausible. It is likely that wounding by $\mathrm{H}$. halys increases susceptibility of fruits to bacterial soft rot, however controlled studies using Koch's postulates and insect dissection would be necessary to elucidate the relationship.

Due to low population counts of $H$. halys it is difficult to accurately evaluate the effectiveness of the trap crops employed. Fewer adults and more nymphs were present on tomato plants surrounded by sunflower than controls. While the trends were statistically significant, further replication and better sampling techniques are needed to recommend planting sunflowers as a form of control. There is currently a multi-university study underway looking at the effect of sunflower (Helianthus annus) and sorghum (Sorghum bicolor) as trap crops for $\mathrm{H}$. halys in sweet pepper (Capsicum annum cv. Aristotle)

Pease and Zalom (2010) found that numbers of stink bug (Euschistus conspersus and Thyanta pallidovirens) egg masses parasitized by predatory wasps increased when tomato fields were bordered by sweet allysum, Lobularia maritima, compared to a mowed edge. They also found that numbers of stink bug on the edge of tomato plots is increased when surrounded by weeds compared to a mowed edge at the beginning of the season, however the effect was found to be absent in the middle and latter portions of the growing season. The authors wrote that it is common to find greater numbers of stink bugs on the edge of tomato fields than the interior. It is not known if $H$. halys follows this pattern. A field release near control and trap cropped plots using harmonic radar tracking (Lee et al. 2013a) may be a good option for gaining a better understanding of how $\mathrm{H}$. halys locates food sources in tomato plots and how trap crops affect its selection. 


\section{Conclusions}

1. Under low population pressure, $H$. halys density in tomato fields with sunflower trap crops may be lower for adults, however further study is required to determine the reliability of trap cropping for management of $H$. halys.

2. H. halys population densities were too low in the field studies conducted to verify whether larger populations of $H$. halys or other pentatomids lead to higher rates of infection by Colletotrichum spp. and causal agents of bacterial soft rot.

3. Feeding scars characteristic of those made by $\mathrm{H}$. halys and other stylet feeding insects are positively and significantly correlated with incidence of anthracnose and bacterial soft rot under low population pressure. 


\section{Chapter II. Correlation of $\boldsymbol{H}$. halys feeding and anthracnose incidence and elucidation of mode of transmission}

\section{Introduction}

Since its introduction in 1996, $H$. halys has been identified in nearly every non-arid state in the US. However, it is considered a severe agricultural pest only in MD, PA, WV, VA, and NJ (Zhu et al. 2012). It has over 300 economic plant hosts including apple, peach, plum, cherry, pepper, and tomato (Zhu et al. 2012).

Anecdotal evidence from both researchers and growers indicates that yield loss in tomato production due to rot pathogens is higher when there is a large infestation of $H$. halys. However, no pathology studies have examined the correlation between $H$. halys population density and prevalence of rot pathogens on harvested fruits.

The most common rot disease affecting tomato fruits is anthracnose, caused by Colletotrichum spp. Anthracnose lesions are not typically visible until the fruit is ripe or overripe. On red fruits, lesions are dark, sunken, and move outward in concentric circles. Setae may become visible as black or brown dots on the inner portion of the lesion as it develops, and turn more of the fruit black as the lesion develops. Under high humidity acervuli containing millions of conidia are visible in slimy salmon-colored droplets (Agrios 1997). Colletotrichum spp. overwinter in the soil, on tomato seed, on infested tomato debris, and are fairly ubiquitous in the environment (Dillard and Cobb 1998; Cannon et al. 2012).

To further elucidate the relationship among the pathogen, its host, and potential insect vector, several transmission studies were conducted. The objective was to determine whether $H$. halys was able to spread Colletotrichum propagules from infected tomato fruits to healthy ones. Body parts of $\mathrm{H}$. halys that had fed on infected tomato fruit were cultured to determine if infective spores could be carried phoretically. Finally a field experiment compared anthracnose levels on tomato fruit clusters exposed to $0,1,3$ and $9 H$. halys nymphs for 5 and 10 days.

\section{Materials and Methods Insects}

H. halys adults were collected in fall 2012 from the barn of a farm in Morgantown, WV, and placed in $35 \times 35 \times 60-\mathrm{cm}$, or $30 \times 30 \times 30-\mathrm{cm}$ insect observation and rearing cages (Bioquip Products $($, Rancho Dominquez, CA). H. halys adults were kept in either the laboratory at $23 \pm 2^{\circ} \mathrm{C}$ or greenhouse at $25 \pm 4^{\circ} \mathrm{C}$. Insects received a 16 -hour photoperiod under full-spectrum fluorescent lights (F40T12/VCX Verilux Inc. Waitsfield, VT) in the laboratory or under metal halide HS2000 lights (P.L. Light Systems, Beamsville, ON) in the greenhouse. Greenhouse cultures received supplemental light when the natural light levels dropped below 330 watts $/ \mathrm{m}^{2}$. Insects were fed several cultivars of organic green bean, Phaseolus vulgaris cv. Royal Burgundy, Yellow Wax, Jade, or Provider (Johnny's Selected Seeds Co. Fairfield, ME) Peperomia clusiifolia, (Ikea $\AA$, Pittsburg, PA), and Kroger Brand $®$ unsalted, raw peanuts, tied to small bamboo stakes using twist ties.

Care for nymphal stages 
Egg masses were harvested from the undersides of bean leaves by cutting the part of the leaf upon which the egg masses were laid against a piece of cardboard using a 6-mm-diam cork borer. Cut sections of leaf were placed in a plastic 3\%1/4-ounce clear ramekin (Solo P325 Solo Cup Company, Urbana, IL) with the egg mass facing up. Up to eight egg masses occupied a ramekin. A 1-cm long by $1-\mathrm{cm}$ diam. cotton cylinder was soaked with distilled water and placed inside and a lid with four air holes was placed on top to maintain proper air exchange and moisture levels. Distilled water was added to the cotton plug as needed. First instars emerged from egg masses and drank from the cotton plug. Once the majority of nymphs in a ramekin had molted to second instar they were placed inside $30 \times 30 \times 30-\mathrm{cm}$ insect rearing and observation cages with bean plants, $P$. clusiifolia and peanuts tied to bamboo stakes. Insects were starved in cages with only water for 48 hours prior to experimentation to encourage feeding.

\section{Colletotrichm Isolates}

Isolate WV12 was a Colletotrichum coccodes s.I. isolate obtained from the anthracnose lesion of a pepper fruit, Capsicum annuum cv. Olympus, grown on the WVU Organic Farm in summer 2012. The anthracnose lesion was excised from a dehydrated pepper fruit, surface disinfested with $1 \% \mathrm{NaOCl}$, triple washed in distilled water, placed on potato dextrose agar (PDA) and incubated at room temperature $\left(23 \pm 2^{\circ} \mathrm{C}\right)$. Conidia were not measured. The isolate will be referred to as being Colletotrichum coccodes sensu lato. Isolation and reculturing was performed by Dr. Mafuz Rahman.

Isolate WV13 was a Colletotrichum isolate obtained from the anthracnose lesion of a Washington Cherry tomato fruit grown on the WVU Organic Research Farm in summer 2013. Cultures of isolate WV13 matched characteristics of the Colletotrichum acutatum species complex (Damm et al. 2012) with cottony white-to gray mycelium growing in concentric rings, pink conidial masses, and deep red-to burgundy pigmentation visible from the underside of yeast extract sucrose agar (YES). DNA extraction was performed. BLAST analysis of ITS and GAPDH gene sequences were used to perform searches in Genbank and revealed the isolate to be within the Colletotrichum acutatum species complex (Damm et al. 2012). The isolate showed $100 \%$ sequence identity to $C$. acutatum (accession \# AJ749672.1) and C. fiorinia (accession \# JN121190.1). The isolate will be referred to as being Colletotrichum acutatum sensu lato.

Colonies of WV13 were grown on YES at room temperature $\left(23 \pm 2^{\circ} \mathrm{C}\right)$ and produced oblong conidia 12-20 x 4-8 $\mu \mathrm{m}$. YES was composed of $4.0 \mathrm{~g}$ yeast extract, $20.0 \mathrm{~g}$ sucrose, $15.0 \mathrm{~g}$ agar, and $1.0 \mathrm{~L}$ of distilled water. Streptomycin was added to the medium after autoclaving for initial isolation from tomato fruit.

\section{Sleeve trial}

On August 25, 2013 a controlled feeding trial was conducted using plants grown for field experiments that season. Insect mesh was cut and stapled into cylindrical sleeves. Two-liter clear plastic soda bottles were washed in bleach and soap and thoroughly rinsed. Tops and bottoms were cut off. Sleeves, then soda bottles were secured around a single fruit cluster. $H$. halys nymphs (Fourth and fifth instars) were then placed inside. There were four to six fruits in each cluster. Treatments of $0,1,3$, or 9 insects were applied to fruit clusters and left in sleeves 
for periods of 5 and 10 days. Each treatment was replicated six times. Dead insects were replaced with live ones daily. At the end of the treatment period, tomato fruits were harvested and incubated for 7 days at room temperature $\left(23 \pm 2^{\circ} \mathrm{C}\right)$, then disease and insect injury parameters were assessed as presence/absence. Anthracnose was identified by blackened lesions which formed outwardly expanding concentric water-soaked lesions (Fig. 1.2). Sporulating infections were scraped, and spores were confirmed as Colletotrichum sp. by microscopy and with reference to Barnett and Hunter (1972). Bacterial soft rot was identified in fruits having a swollen, watery region, with little to no discoloration (Fig.1.3). Black spotting was defined as fruits with black lesions exhibiting symptoms characteristic of other rot pathogens such as bacterial spot, Fusarium spp. Rhizoctonia solani or Alternaria solani. These were described based on the findings and descriptions of Gutierrez et al. (2006) and Agrios (1997). Stylet feeding scars were identified as characteristic cloud scars that form on tomato fruits after H. halys feeding (Fig. 1.4). Fruits were given a binary marketability score based on several characteristics. Fruits were rated as unmarketable if they had an anthracnose lesion $>2 \mathrm{~mm}$, or five or more feeding scars present, or if soft spots were present or if black spotting covered $>30 \%$ of the fruit surface.

\section{Data analysis}

Data on tomato fruits within each sleeve were averaged and used as experimental units. Normality of data was tested using the Shapiro-Wilk $W$ test by treatment factor using number of stink bugs and days of exposure. The variables Anthracnose Incidence and Bacterial Soft Rot incidence had $12 \%$ or less not normally distributed groups, so parametric methods (ANOVA) in a $4 \times 2$ factorial design were used, and means were compared using the Dunnet multiple comparison test. The variables Black Spotting, Cracking, Marketable, Healed Crack, Mold and Soft Rot had more than $15 \%$ not normally distributed data, so nonparametric methods were used (Kruskal-Wallis one-way analysis and the Wilcoxon multiple comparison method) to analyze these variables. Data were analyzed using JMP and SAS software.

\section{Incubator trial}

\section{Treatment Acronyms Used}

The following are acronyms used to describe treatments in the Incubator Trial, and Anthracnose Transmission in a Greenhouse Setting

$\mathrm{C}=$ control

$\mathrm{IO}=$ inoculum only; refers to treatments where $C$. acutatum inoculum was added with no $H$. halys added

$\mathrm{SBI}=$ stink bugs + inoculum; refers to treatments where $H$. halys are added

simultaneously to $C$. acutatum inoculum

SBT = stink bug transmission; refers to treatments where $H$. halys was exposed to $C$.

acutatum and was then placed with healthy tomato fruit for feeding

$\mathrm{SBO}=$ stink bug only; refers to treatments where $H$. halys was removed directly from laboratory cultures to feed on healthy tomato fruit

SBW = stink bug wounded; refers to treatments where $H$. halys was exposed to fruits, then removed and inoculum was sprayed 
In Fall 2012, plastic cake clamshells made from oriented polystyrene plastic were obtained from the local grocery store for an incubator feeding trial. Fourth and fifth instar $H$. halys nymphs were obtained from laboratory cultures and starved for 12 hours without water prior to experimentation. A single plate of sporulating 20-day-old Colletotrichum (isolate WV12) growing on PDA was flooded with sterile distilled water, scraped with a sterilized metal cell spreader and diluted to a solution of $10^{6}$ conidia/ $\mathrm{mL}$. The inoculum was placed in a spray bottle which was previously disinfested with bleach, and applied as a mist to treatment groups receiving inoculum. Tomato fruits, Solanum lycopersicum cv. Black Cherry, were obtained from the West Virginia University Organic Research Farm (Morgantown, WV) in September 2012. Fruits were soaked for $2 \mathrm{~min}$ in $1 \% \mathrm{NaOCl}$; then triple-washed with sterile distilled water. Tomato fruits were then placed in clamshells where treatments were applied. There were seven tomatoes per replicate and three replicates per treatment. Seven $H$. halys nymphs (fourth and fifth instar) were added to clamshells for treatments with $H$. halys (SBI, SBT, and SBW).

In the control (C) treatment, sterile distilled water was sprayed inside the clamshell to the point of fruit wetness. In the inoculum only $(\mathrm{IO})$ treatment, tomato fruits were sprayed with WV12 to the point of saturation. No insects were added. In the stink bugs + inoculum (SBI) treatment, WV12 was sprayed on tomato fruits to the point of run off. $H$. halys nymphs were then placed on fruits. In the stink bug transmission treatment (SBT), H. halys nymphs were placed inside a petri dish of WV12 on potato dextrose agar for 24 hours and then were transferred to a clamshell filled with tomatoes. In the stink bug wounding (SBW) treatment, $H$. halys nymphs with no known exposure to Colletotrichum spp. were added to fruits. After 7 days, insects were removed, and WV12 was sprayed inside to the point of fruit wetness.

All 'clamshells' were placed inside a Percival I36VLC8 incubator (Percival Scientific, Perry, IA) at $22 \pm 2^{\circ} \mathrm{C}$ with a 16 -hour photoperiod. Dead insects were replaced with live ones daily from a stock of surplus insects kept in plastic ramekins with only water soaked cotton plugs. Disease incidence of anthracnose, other rots, and total diseased fruit were recorded at 10,17 , and 21 days. Other types of rot included an unidentified white mold and a grey mold which appeared to be a Botrytis spp. Identity of these organisms was not confirmed, nor was a pathogenic relationship confirmed. Anthracnose infections were identified by lesions which formed outwardly expanding concentric water-soaked lesions (Fig. 1.2). Blackened tissue did not form on anthracnose infections, presumably due to cultural conditions, although the precise causal agent is unknown. Sporulating infections were scraped, and spores were confirmed as Colletotrichum spp. using Barnett and Hunter (1972).

\section{Data analysis}

A Poisson Proc GENMOD Regression analysis was performed comparing all treatments to controls for anthracnose incidence, other diseases, and total diseased fruits. A KruskallWallis test was applied using nonparametric one-way ANOVA, and the Wilcoxon Method was used to compare anthracnose incidence and other disease incidence at individual sampling times. Data were analyzed using JMP and SAS software (JMP ${ }^{\circledR}$, Version Pro 11, SAS Institute Inc., Cary, NC, Copyright (C2013; SAS ${ }^{\circledR}$, Version 9.3, SAS Institute Inc., Cary, NC, Copyright (C)2002-2010). 


\section{Greenhouse trial}

Plants

Organic tomato seed, Solanum lycopersicum cv. Washington Cherry, from Johnny's Selected Seeds (Fairfield, ME), was planted in plug trays and placed in a mist bed the West Virginia University Greenhouse in winter 2013 and winter 2014. Seedlings were transplanted to 9.5-cm-diameter pots 8 days after planting, and transplanted to 15-cm-diameter pots 30 days after planting. The soil medium was 1:1:1 perlite: peat moss: compost. Compost was obtained from the WVU Organic Research Farm. Bloodmeal was given as a nitrogen source and was applied at a rate of $5 \mathrm{~mL}$ per plant at each transplanting, and bonemeal was used as a phosphate source and applied directly to the soil media at a rate of $5 \mathrm{~mL}$ per plant at transplanting. Plants were kept in the same greenhouse room as $H$. halys cultures with the same photoperiod and temperature.

The experiment was conducted in March 2013, and repeated in March 2014. WV12 was used as an inoculum source in March 2013, WV13 was used in March 2014. To make inoculum solutions, a single plate of the culture was flooded with sterile distilled water, scraped with a sterile cell spreader and diluted to a solution of $10^{6}$ conidia/ $\mathrm{mL}$. The inoculum was placed in a spray bottle which was previously disinfested with bleach, then applied as a mist to the point of fruit wetness to treatment groups receiving inoculum.

\section{H. halys infestation with Colletotrichum for SBT Treatment}

Tomato fruits, harvested from the plants grown for the experiment, were surface sterilized for 2 minutes in $1 \% \mathrm{NaOCl}$, then triple-washed with sterile distilled water. Four holes were poked in each tomato fruit, using a 40-um-diam dental pulp canal file sterilized with alcohol and washed with sterile distilled water, then a solution containing $10^{6}$ spores $/ \mathrm{mL}$ of WV12 or WV13 (WV12 was used in the first trial WV 13 was used in the second) in distilled water was applied to the surface of the fruit. Each fruit was incubated in a plastic ramekin with a cotton plug soaked in spore solution to maintain humidity. Four aeration holes were poked in the lid, and the ramekin was placed in an autoclaved plastic bag and sealed for 48 hours. Five days later lesions appeared on tomato fruit. Fruit were then placed in a 30X30X30-cm insect observation and rearing cage. H. halys were starved for 48 hours with water, then placed for 48 hours in a $30 \times 30 \times 30-\mathrm{cm}$ insect rearing and observation cage containing the Colletotrichuminfected fruit as the only food source.

\section{Experimental Design}

Treatments were applied to tomato plants 60 days after planting. Plants with four or more ripe fruits were placed in a $35 \times 35 \times 60-\mathrm{cm}$ insect rearing and observation cage, and treatments were applied. All cages, regardless of treatment, were placed in a moist chamber. Moist chambers were constructed out of trash bags taped together, and a 31/4-ounce clear plastic ramekin with distilled water was placed inside to maintain humidity. One of three types of sprays were applied: no spray applied, sterile distilled water sprayed to the point of fruit wetness, or Colletotrichum inoculum (WV12 for the first trial, WV13 for the second) at a 
concentration of $10^{6}$ spores $/ \mathrm{mL}$ was sprayed to the point of fruit wetness. Plants were sprayed in a separate room to minimize the possibility of cross-contamination. Cages were incubated for 10 hours overnight, and moist chambers were disassembled. Four male and four female $H$. halys adults were added to three of the treatments. Treatments were as follows:

The control (C) treatment received a spray of sterile distilled water. The inoculum only (IO) treatment received only a spray of Colletotrichum to the point of fruit wetness. The stink bugs + inoculum (SBI) treatment received a spray of Colletotrichum to the point of fruit wetness, and $H$. halys were added to the insect cage immediately afterward. The stink bug transmission (SBT) treatment, received $H$. halys adults that had fed on infected fruit for 48 hours. No water was sprayed in the cage, although the cage was placed in a moist chamber at the same time as other treatments. The stink bug only (SBO) treatment received $H$. halys adults that were placed inside a cage with a healthy tomato plant with no inoculum or water sprayed although the cage was placed in the same type of moist chamber as other plants. In all treatments, insects were removed at 10 days.

Two cages were maintained as a source of replacement for dead insects. Replacement H. halys adults for uninfested insect treatments (SBO and SBI) were kept in an insect cage with a healthy tomato plant throughout the experiment. A separate cage with $H$. halys adults feeding on Collteotrichum-infected tomato fruit was maintained as a source of replacement for dead insects for the SBT treatment. Stink-bug mortality was recorded daily. Dead insects were replaced daily.

Fruit were harvested as they ripened over a period of 10-17 days from the start of the experiment. Harvested fruit were incubated at room temperature $\left(23 \pm 2^{\circ} \mathrm{C}\right)$ for 10 days. Infections were recorded as being anthracnose, or other type of rot. Anthracnose was identified by blackened lesions which formed outwardly expanding concentric water-soaked lesions. Fruits with sporulating infections were scraped; scrapings were placed on a slide, and spores were inspected under a compound microscope and confirmed as Colletotrichum spp. using Barnett and Hunter (1972). The number of diseased fruit was recorded and the percentage of fruit in each cage that either had anthracnose or was affected by another type of rot was calculated.

\section{Data Analysis}

Data were analyzed using the SAS statistical program (SAS Institute). A Kruskall-Wallis test was applied using nonparameteric one-way ANOVA and a difference level of $P<0.10$ was used to separate means. Due to lack of balance in ripeness amongst cages, tomatoes were classified as early, middle or late harvest. Experimental units were therefore defined as cageharvest period. Tomatoes harvested 10,11, and 12 days from the start were classified as early; tomatoes harvested 13,14 , and 15 days from the start were classified as middle harvest; tomatoes harvested 16 and 17 days from the start were classified as late harvest. Eight cageharvest periods lacked harvestable tomatoes, therefore 52 experimental units were derived from five treatments.

\section{Fungal isolation from body parts of $\boldsymbol{H}$. halys feeding on detached tomato fruit}

Eight $30 \times 30 \times 30-\mathrm{cm}$ insect cages were used for each treatment. A mix of three juvenile and adult $H$. halys were placed inside each cage, with a tomato fruit. Adults and juveniles were 
unevenly mixed due to lack of production in the culture (data not shown). $H$. halys were exposed to one of two treatments: tomato fruits infected with Colletotrichum or surface sterilized untreated tomato fruits.

\section{Fruit inoculation}

Organic plum tomato fruits were obtained from a local supermarket, surface sterilized for 2 min using 1\% $\mathrm{NaOCl}$, then triple-washed with sterile distilled water. Four holes were poked in each tomato fruit, using a 40- $\mu$ m dental pulp canal file sterilized with alcohol and washed with sterile distilled water, then placed in a plastic ramekin with a dry cotton plug. A solution of $10^{6}$ spores $/ \mathrm{mL}$ of WV13 in sterile distilled water was poured over the surface of the fruit and onto the cotton plug. A lid with four aeration holes was placed on the ramekin, and the ramekin was placed in an autoclaved plastic bag to maintain $100 \%$ humidity for 48 hours. Five days later lesions appeared on tomato fruit. Fruits were then placed in insect cages with $H$. halys.

\section{Preliminary trial}

A preliminary trial was conducted to determine if propagules could be successfully cultured from $H$. halys. Cages with infected and uninfected tomatoes were established and insects were placed inside. After 7 days of feeding, six washings of adult stink bugs were cultured on YES. Sterile distilled water was placed inside a new 500-mL wash bottle (Polylab ${ }^{\circledR}$ Singhla Scientific Industries, Harayana, India) immediately after it was removed from its plastic packaging. The wash bottle was a squeeze type that releases water under hand pressure. Three washings were made of controls ( 2 females, one male) and three were made of insects feeding on infected tomatoes ( 2 females, one male). Eighty microliters of the washing were micropipetted from the beaker onto a $5.5-\mathrm{cm}$ petri dish containing YES $+250 \mathrm{ppm}$ streptomycin medium and spread with a sterile cell spreader. Additionally 3 insects ( 2 nymphs, one male adult) feeding on infected tomatoes were dismembered, and stylets and legs were placed on the same YES + 250 ppm streptomycin media. Samples were wrapped in parafilm and incubated at room temperature $\left(23 \pm 2^{\circ} \mathrm{C}\right)$ for 10 days. Successfully isolated cultures were used to infect healthy surface-sterilized supermarket grape tomatoes to verify pathogenicity.

\section{Main trial}

$H$. halys adults and nymphs were starved with water for 72 hours prior to placement in insect cages with tomato fruit for 7 days. On day seven, each insect was surface washed using sterile distilled water. Each insect was held over a sterile, autoclaved beaker using gloved hands (gloves were sterilized with alcohol between handling of insects), and an unmeasured amount of sterile distilled water was passively poured over the body of the insect into the beaker. Washings were cultured in the same manner as the preliminary trial above. A single rear leg, and the whole proboscis including the stylet were then removed from each insect and placed on YES +250 ppm medium. Fisherbrand (Fisher Scientific Pittsburgh, PA) filter papers were sterilized via autoclave $\left(121^{\circ} \mathrm{C}\right.$ at 15 psi for $\left.15 \mathrm{~min}\right)$ and placed on the floors of control insect cages, and those with infected tomatoes. Droppings made on filter papers were cut and placed faced down on YES +250 ppm streptomycin. Only 5 droppings from infected cages, and 4 droppings from control cages were obtained. Samples were wrapped in parafilm and incubated 
at room temperature $\left(23 \pm 2^{\circ} \mathrm{C}\right)$ for 10 days. At day ten, cultures were visually inspected and presence/absence of Colletotrichum was recorded. DNA was extracted from isolates taken before and after isolation from stink bugs. Portions of the ITS and GAPDH genes were PCR amplified and sequenced. The primers ITS4 and ITS5 were used for ITS PCR amplification; conditions and sequencing were performed as reported in White et al. (1990). The primers VGPDf and VGPDr were used for GAPDH amplification; conditions and sequencing were performed as reported in Inderbitzin et al. (1990). BLAST searches were performed in GenBank. Additionally, an Align Sequences Nucleotide BLAST analysis was performed to compare the homology of sequences of inoculum obtained from $\mathrm{H}$. halys to the original inoculum used to infect tomato fruits (See Appendix). Successfully isolated cultures were used to infect healthy surface-sterilized supermarket grape tomatoes to verify pathogenicity.

\section{Data analysis}

Data were analyzed using the SAS statistical program (SAS Institute). Treatment comparisons were performed between treatments for stylets and legs individually as well as combined using the nonparametric Wilcoxon test. The cage was used as the experimental unit for these analyses. A frequency analysis using the Fisher's Exact Test was performed using individual stink bugs as experimental units.

\section{Results}

\section{Sleeve trial}

All treatments with $\mathrm{H}$. halys had significantly more anthracnose than controls (Fig 2.1). The experiment was carried out late in the life of the tomato plants (81-91 DAT) and the rate of Colletotrichum infection was 51\% (2013 see Fruit Rot Sampling Results Ch.1, p. 17). Additionally, rainfall was higher than average for this time of year (Table 1.2). All treatments except for zero stink bugs at 5 days had $>50 \%$ anthracnose incidence. Number of insects per sleeve accounts for more of the variance observed in Colletotrichum incidence than days in sleeve (Table 2.1). The same trend shown in Fig. 2.1 was true of bacterial soft rot, however differences were significant only between zero stink bugs versus 1,3 , and 9 stink bugs ( $P=0.0146)$. Number of stink bugs explained a significant amount of the variance observed in bacterial soft rot incidence $(P=0.0409)$. Marketability did not differ among treatments with 1,3 , and 9 stink bugs for either feeding period, however the treatment with no stink bugs had significantly more marketable fruit for both feeding periods than all treatments with stink bugs $(P<0.0596)$. While all treatments with stink bugs had a greater incidence of stylet-feeding insect scars than the control, no significant differences occurred among treatments with 1, 3 or 9 stink bugs. All fruit clusters with stink bugs had greater than $60 \%$ of the fruit with stylet feeding insect scars. No significant differences occurred in cracked fruits, black spotting, or mold incidence.

\section{Incubator trial}

Disease moved quickly through the stink bugs + inoculum treatment (SBI) (Fig. 2.2). All but one of 21 fruits in SBI had anthracnose by day 7 of the experiment. The clamshells of SBI 
retained free moisture throughout the experiment. Other treatments didn't maintain free moisture past the third day of the experiment.

Inoculated treatments (IO, SBI, SBT, and SBW) had significantly higher anthracnose incidence and total diseased fruit than the control $(C)(P<0.05)$. SBI had the greatest incidence of anthracnose, other diseases, and total diseased fruits at all three sampling times (Figs 2.3 and 2.4). Anthracnose incidence differed between SBI and all other treatments according to the Wilcoxon test at all three sampling times (Experiment-wise comparison of $\mathrm{P}<0.077$ ), except at day 21 when SBI and SBW (stinkbug wounded) treatments did not differ (Fig. 2.3).

Anthracnose incidence in the stink bug transmission treatment (SBT) did not differ from the control at 10 and 17 days, but did differ significantly on day 21 ( $P<0.077)$ (Figs. 2.3). Anthracnose incidence in IO was significantly lower than in SBI at the first two sampling periods, but not the third. At no sampling period did the Colletotrichum inoculum only treatment (IO) differ significantly in anthracnose incidence from the control treatment, however the two differed when averaged across sampling periods $(P<0.10)$. At days 17 and 21 the difference was not significant with a probability of difference at alpha=0.12.

Most 'other diseases' occurred on fruits already infected with Colletotrichum. Trends from anthracnose incidence remained consistent in total diseased fruit, however fewer differences were significant at day 21 (Fig. 2.4).

\section{Greenhouse trial}

All treatments with Colletotrichum inoculum differed significantly in anthracnose incidence from treatments without (Fig. 2.5). SBI ( $n=11)$ had significantly higher anthracnose incidence than all other treatments. IO $(n=9)$ and SBT $(n=11)$ did not differ in anthracnose incidence, nor did C $(n=11)$ and SBO $(n=10)$. Non-control treatments did not differ from each other in total diseased fruit, but did differ significantly from the control $(P<0.05$, Fig. 2.6). Correlation analysis based on individual tomatoes revealed that anthracnose infection was positively correlated $(R=0.3939)$, with feeding scars $(P=0.0051)$. Total infected fruit was also positively correlated $(R=0.4582)$ with feeding scars $(P=0.0043)$.

\section{Fungal isolation from body parts of $H$. halys feeding on detached tomato fruit}

\section{Preliminary trial}

Two of three of the washings plated resulted in infective $C$. acutatum cultures. Additionally, two out of three stylets and legs respectively resulted in infective $C$. acutatum cultures.

\section{Main trial}

Feeding was observed in all cages, and stylet sheaths were numerous on all tomatoes. No washings or body parts from control treatments yielded a culture of $C$. acutatum, whereas $37.5 \%$ of insects feeding on infected fruit yielded a Colletotrichum culture (Fig. 2.7). All of these cultures successfully re-infected healthy tomato fruit.

At the end of the experiment most $H$. halys individuals that started the experiment as nymphs had molted to adults. Of the 42 insects in the experiment, only seven remained 
nymphs at the end. Three nymphs were in cages with $C$. acutatum infected fruits, four nymphs were in control cages. None yielded $C$. acutatum cultures. Two $H$. halys in infected treatments and one in a control cage died during the experiment. All were fourth instar at the conclusion of the experiment.

Of the 20 insects feeding on infected tomatoes, C. accutatum was isolated from five stylets and seven legs (Figs. $2.8 \& 2.9$ ). No insects feeding on healthy fruit yielded a $C$. acutatum culture. Ten of these twelve cultures were axenic. Of the 42 washings plated, none resulted in a C. acutatum culture. Most plates either had no fungal growth, or yielded fungal cultures that are not known tomato pathogens. Of the nine droppings plated ( 5 from cages with infected tomatoes, 4 from control cages), none resulted in cultures of $C$. acutatum. None of the body parts, washings, or droppings from controls resulted in C. acutatum cultures.

BLAST searches of ITS sequence data for each of eight Colletotrichum isolates tested showed $100 \%$ sequence identity to $C$. acutatum. The isolates with matched sequence identity have since been removed from Genbank however, and cultures with the closest sequence identity are currently $C$. fiorinia. GAPDH gene sequences were generated and found to be $99 \%$ identical to $C$. fioriniae isolate TR-126 (GenBank accession KF944355).

\section{Discussion}

In fields with high disease pressure, it was found that addition of one stink bug to a fruit cluster significantly increases anthracnose incidence. Whether this trend would remain if disease pressure were low is unknown. The sleeve trial represents the first time tomato anthracnose has been measured in the field with known differing feeding levels of $H$. halys. The fact that number of stink bugs was a significant predictor of anthracnose incidence $(P=0.0003)$ and days in sleeve was not $(\mathrm{P}=0.1095)$ is analogous to the findings from a multi-plant row-cover feeding trial (Zalom et al. 1997), where the incidence of feeding scars on tomato was not significantly increased between 8 and 20 days of feeding. It was hypothesized that this occurred because stink bugs do not readily move between plants. The current study only looked at single fruit clusters at a time, whereas Zalom et al. (1997) isolated five plants at a time for feeding. Still there was no significant increase in the incidence of feeding scars on tomato fruits with increased time in sleeve. While days of feeding may affect incidence of feeding scars and anthracnose, this difference is not detectable past 5 days. How long an individual stink bug typically spends in a tomato field when not constrained by a sleeve or row cover is unknown. Using a harmonic radar tag such as the one developed by Lee et al. (2013a) would likely be useful for determining this. If determined, this information would be useful for timing the application of insecticides and understanding the relationship between $H$. halys infestations and anthracnose epidemics.

In the incubator trial, while exposure to $C$. acutatum in the stink bug transmission treatment occurred, no feeding behavior was verified. It is difficult to speculate as to the mode of transmission. Since there was no wetness period in this treatment, it is to be expected that phoretic Colletotrichum transmission would not occur quickly. Spores, once present on the fruit surface, may have required the aqueous droppings of $H$. halys in order to germinate and infect. If spores were transmitted via feeding, they were likely fewer in number in the stink bug 
transmission treatment than the stink bug + inoculum treatment. The difference in free moisture between the two treatments may also account for the initial difference in anthracnose incidence. However this difference disappeared at day 21 , indicating that $H$. halys is capable of transmission of Colletotrichum to tomato fruit without a period of free moisture typically required for infection.

It is apparent that, under these controlled conditions, stink bug feeding with Colletotrichum inoculum leads to much higher anthracnose incidence than presence of Colletotrichum inoculum alone. This was also true in the greenhouse trial. The combination of stink bug wounding, free moisture, and early incidence of disease likely led to the persistently moist conditions in the stink bug + inoculum treatment. However, it is significant that anthracnose spreads much more rapidly when large amount of spores are present in free moisture and stink bug feeding occurs than with large amounts of spores present in free moisture alone. This indicates that during an anthracnose epidemic, when fruit wetness persists for long period of time, $H$. halys infestations may significantly increase anthracnose-induced losses.

In detached fruit studies with Colletotrichum coccodes s.I., Dillard (1989) found wetness periods of 0,3 , and 5 hours resulted in no infected fruit whereas wetness periods of 10, 20, 24, and 29 hours resulted in disease incidence of 35, 75, 92, and 100\% respectively, indicating that a fruit wetness period between 5 and 10 hours is required for infection. In the incubator trial, daily observations of fruit wetness were not made, and perhaps would have been useful for interpretation of the results.

In the Greenhouse trial, while feeding behavior was verified in the stink bug transmission treatment through direct observation and through the observation of stylet sheaths on the infected tomato fruit, feeding was not verified for each individual used in the experiment.

The fact that $C$. acutatum was successfully cultured from $H$. halys stylets and legs following tomato feeding, suggests that $H$. halys is capable of carrying spores of Colletotrichum spp. phoretically. However the observation that none of the washings in the main trial of the experiment resulted in $C$. acutatum cultures suggests that spores readily adhere to the body of the insect, but are not easily separated. The pressure required to separate spores from the body of the insect is likely somewhere between the pressure generated from pouring water over the body of the insect and that generated from the squeeze spray bottle used in the preliminary trial.

Kimura et al. (2008b) performed a similar study with Riptortus pedestris (Heteroptera: Pentatomidae) feeding on soybean infected with Eremothecium ashbyi or E. coryli (Ascomycota). They removed the heads of $R$. pedestris immediately after feeding periods of 1 , 3 , or 5 days and immediately sectioned and stained them. From observation of stained sections, it was determined that 24 of 50 R. pedestris feeding on soybeans infected with either E. ashbyii or $E$. coryli acquired either ascospores or mycelium of the fungi in their stylet pouches. The detections of ascospores via head sectioning was likely a more sensitive test for acquisition of pathogenic propagules than culturing of whole body parts. A separate experiment revealed the presence of $E$. coryli and $E$. ashbyi in the stylet sheaths of $R$. pedestris. The ascospores of $E$. ashbyi and E. coryli acquired by $R$. pedestris and observed were $2.0-3.3 \times 10.0-18.8 \mu \mathrm{m}$. This is 
notably smaller than the 4-8 $\times 12-20 \mu \mathrm{m}$ conidia of WV13. While the diameters of the food and salivary canals are known to range from 8.51 to $15.73 \mu \mathrm{m}$ and 7.92 to $13.49 \mu \mathrm{m}$ respectively in other Pentatomids (Brozek and Herczek 2004), these dimensions are still unknown in $R$. pedestris and $H$. halys. If the diameter of the food and salivary canals of $H$. halys fall within the range of other pentatomids, it is likely that $H$. halys is capable of carrying conidia of Colletotrichum spp. in its stylet pouch.

In order to further elucidate the mechanism of transmission, microscopy studies similar to those of Kimura et al. (2008b) that involve dissection of the stink bug and visualization of conidia inside the stylet pouch and salivary sheath should be conducted. Additionally, the $H$. halys stylet should cross-sectioned and measurements made of its salivary canal and food canal. (An attempt was made to measure the diameter of the food canal and salivary canal of the stink bug, however the stylet was embedded in wax and split apart upon sectioning. Due to the brittle nature of the insect cuticle it is advisable to use plastic as an embedding medium for this measurement.)

These findings indicate that management of $\mathrm{H}$. halys and likely other stink bugs is an important step in managing and preventing losses due to fruit rot pathogens. Row cover that excludes the insect in outdoor tomato production systems is likely the most effective option. Proper biosecurity at greenhouses (including sealing of cracks and holes, and careful inspection of new plant material) to exclude $H$. halys and other pentatomids is an important step for preventing losses associated with their damage.

While pheromone baited pyramid traps are useful for monitoring densities and dispersion of established populations, black light traps are recommended for detection of new populations before damage is present (Nielsen et al. 2013). While pheromone traps were found to increase $H$. halys infestations in home gardens, black light traps, being generally more attractive may, reduce numbers in fields where infestations have already taken hold. This may be a subject for future study however, as black light traps may lure more stink bugs in than would otherwise be present.

$H$. halys presents a threat to tomato agriculture for several reasons. First, it produces a toxin that causes visible damage to the tomato fruit. Second, it is capable of carrying infective spores of Colletotrichum spp. Third, its wounding of tomato fruit leaves them more susceptible to anthracnose and general decay. For these reasons it is advisable to control $H$. halys and other pentatomids in tomato fields.

\section{Conclusions}

4. H. halys is capable of transmitting Colletotrichum spp. from infected tomato fruit to healthy tomato fruit.

5. H. halys is capable of carrying infective Colletotrichum spores phoretically

6. Wounding of tomato fruit by $H$. halys likely leads to greater susceptibility to infections by Colletotrichum spp. 


\section{Figures}

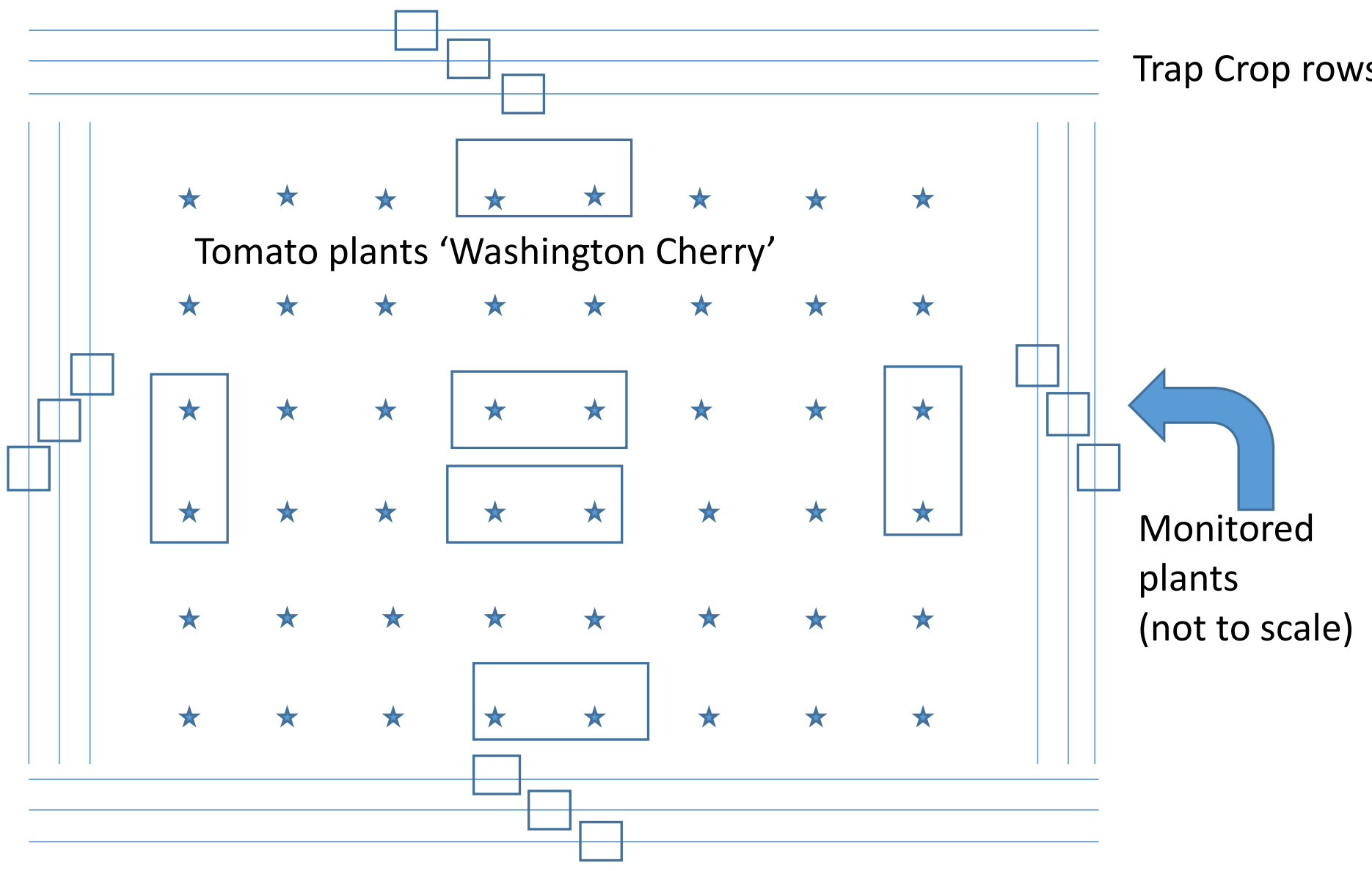

Fig. 1.1. Plot layout and sample points of trap crop plots established in 2013 and 2014. Stars represent individual tomato plants, lines represent rows of trap crop plants. Trap crop plants were direct seeded spaced $15 \mathrm{~cm}$ apart within rows with $91 \mathrm{~cm}$ between rows. Boxes indicate plants used for insect monitoring. The same tomato plants used for insect data were used for disease data. Rye border is not pictured here. 

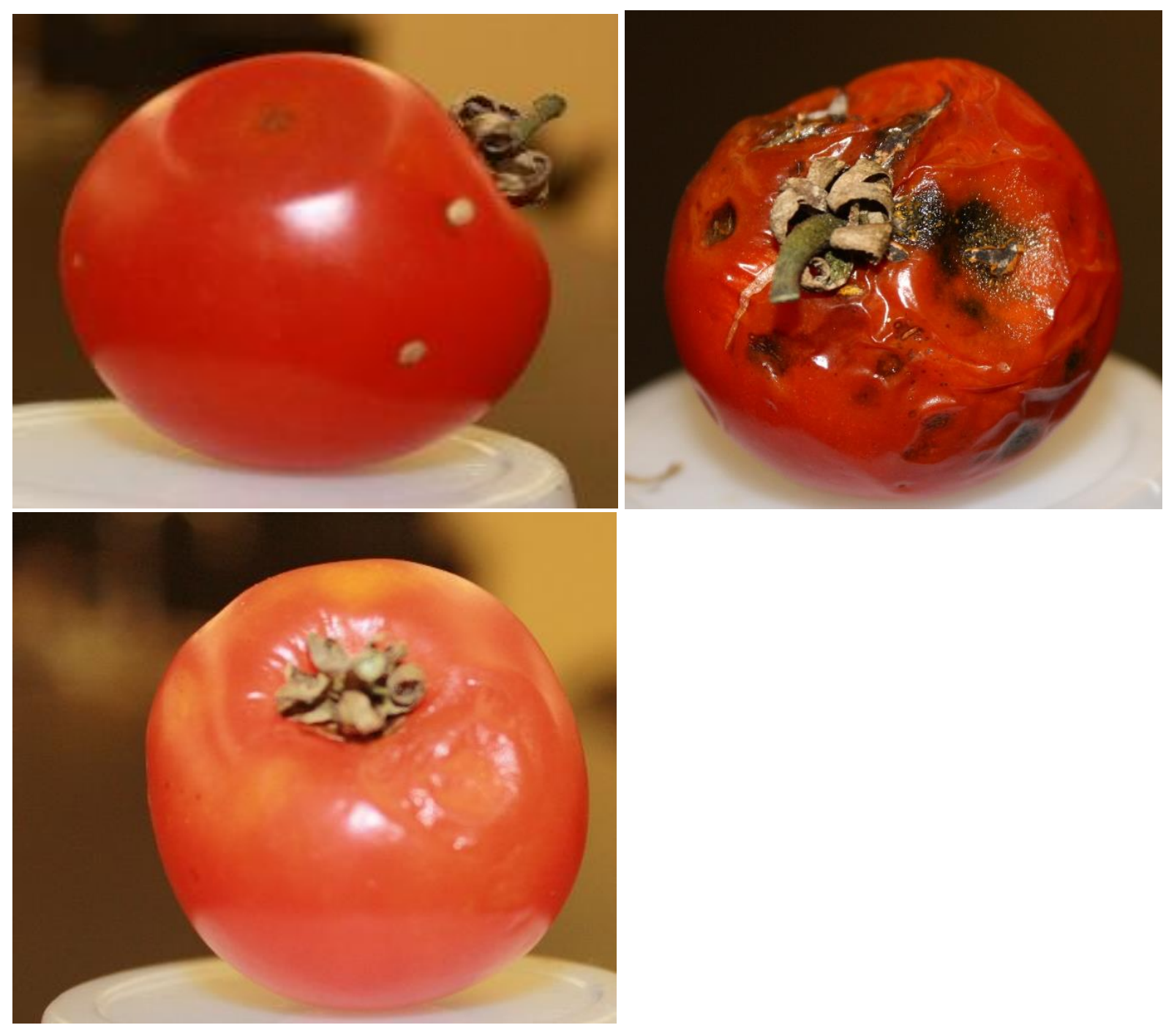

Fig. 1.2 Tomatoes with varying stages of anthracnose. Top left: characteristic blackened sclerotium with acervuli sporulating on top, giving the fruit a greasy appearance. Top right: several black sunken lesions with concentric growth. Note the greasy appearance of sporulating acervuli which yielded many spores of Colletotrichum. Lower left photo: a Colletotrichum lesion with little visible discoloration. 


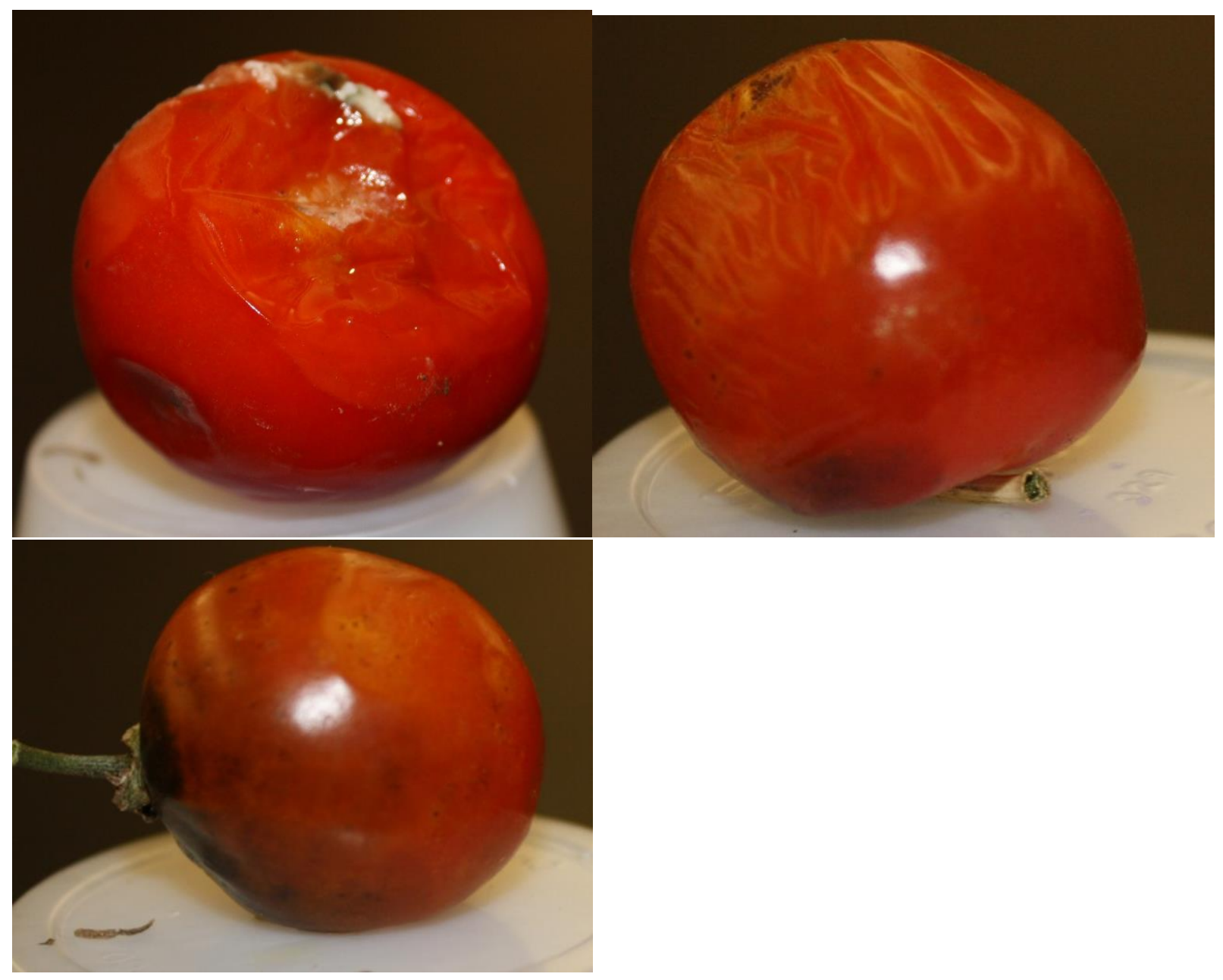

Fig. 1.3. Tomato fruits with bacterial soft rot. Bacterial colonies may have a white appearance, or may lack definite color. Typically the fruit would have a softened quality as is evident in the phots on the top right and bottom left. 


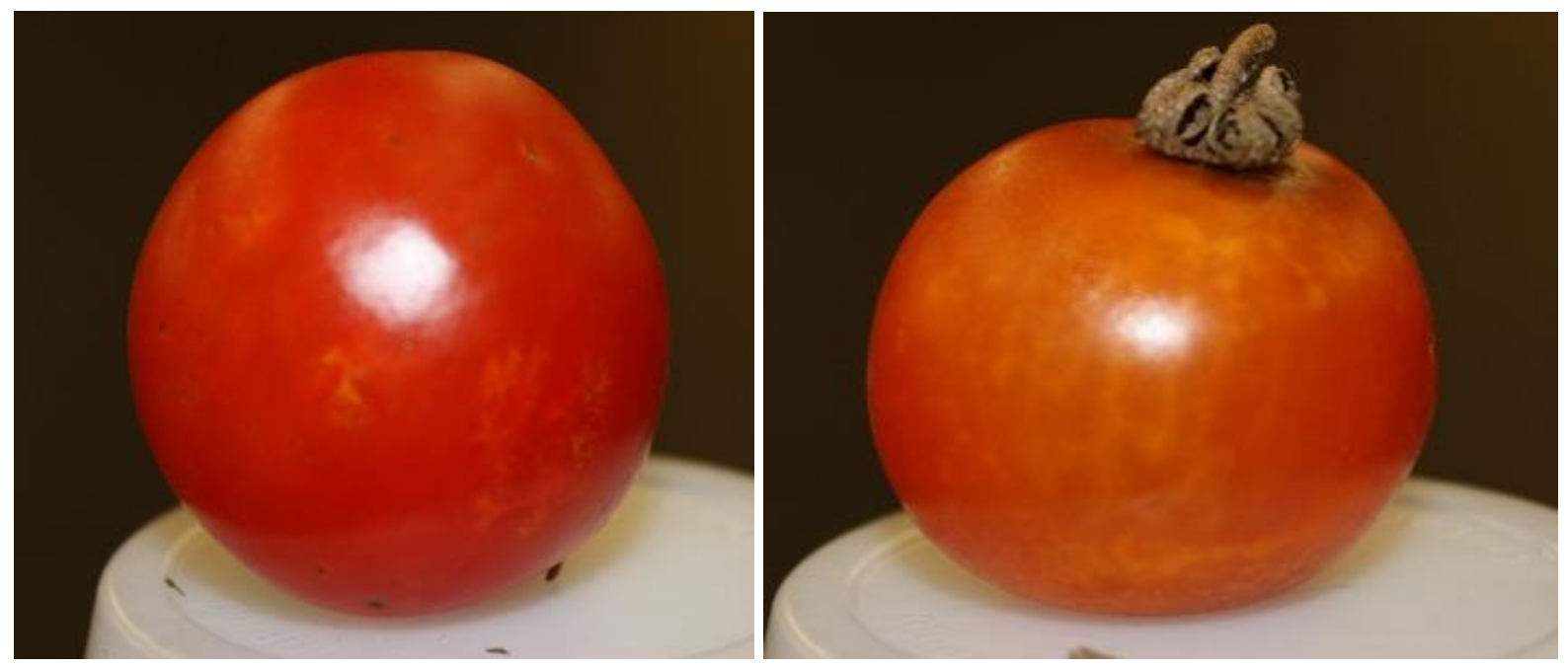

Fig 1.4. Tomato fruits damaged by $H$. halys. The yellow marks are tissue damaged by the feeding of $H$. halys. 


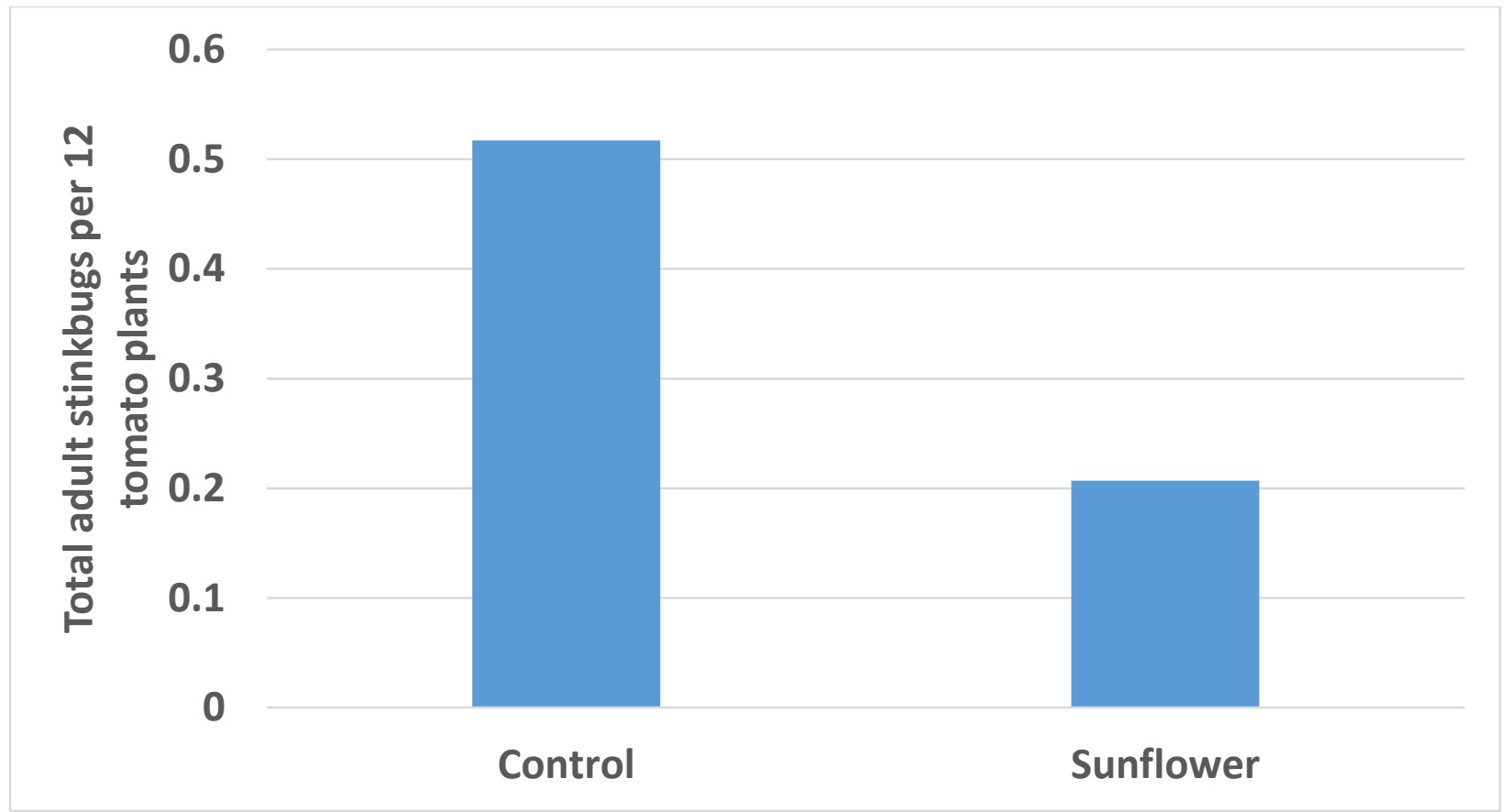

Fig. 1.5. Total average adult stink bugs per tomato plot in 2013 and 2014. H. halys accounted for $79 \%$ of stink bug adults found on tomatoes in control plots, while accounting for only $17 \%$ of stink bug adults found on tomatoes in sunflower trap crop plots. Comparison made using Wilcoxon signed-rank test comparison of means ( $P=0.0468, n=29, z=-1.99)$. 


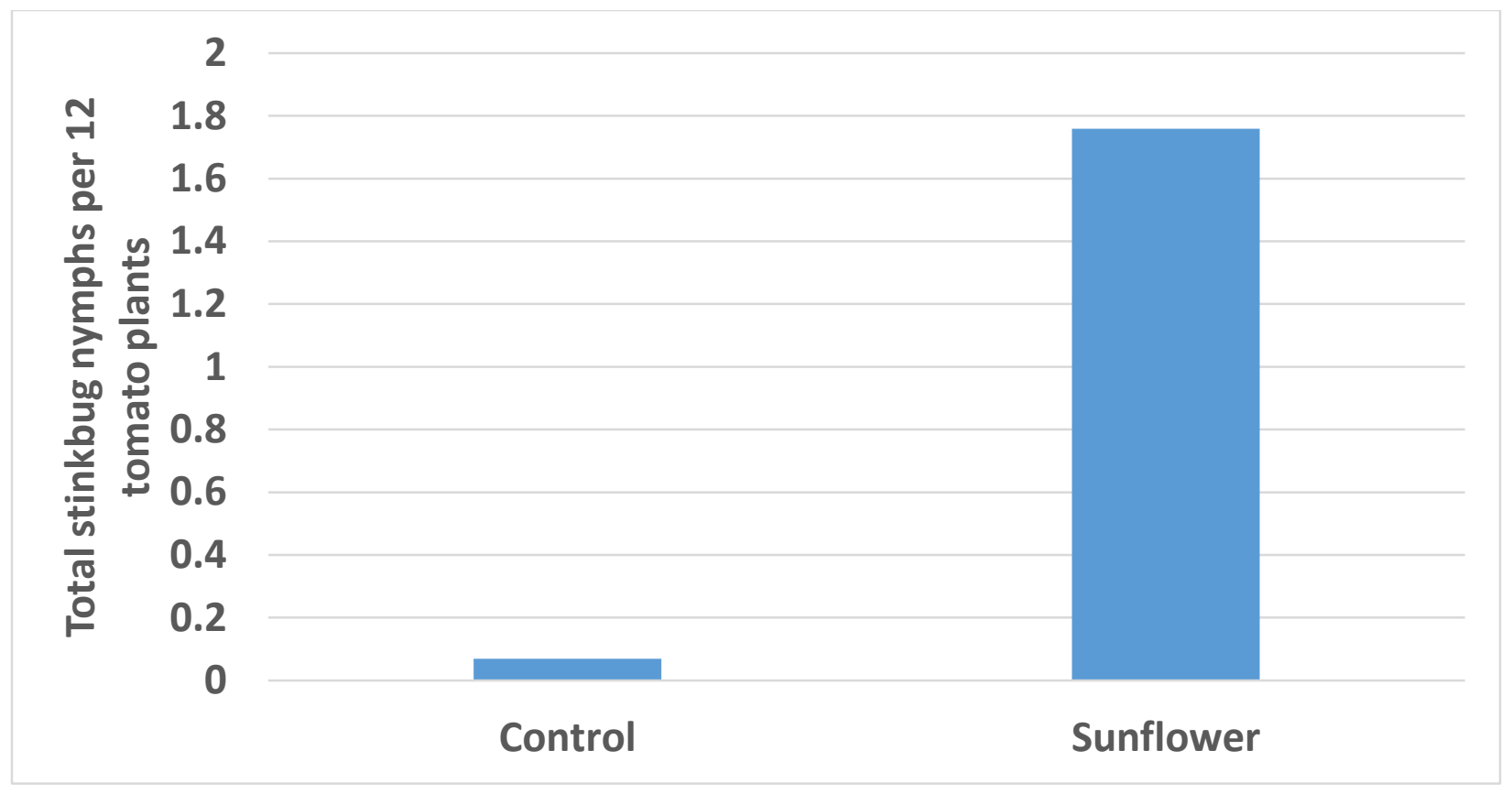

Fig. 1.6 Total average stink bug nymphs per 12 tomato plants in 2013 and 2014. Comparison made using the Wilcoxon signed-rank test $(P=0.34, n=29, z=0.96)$. 


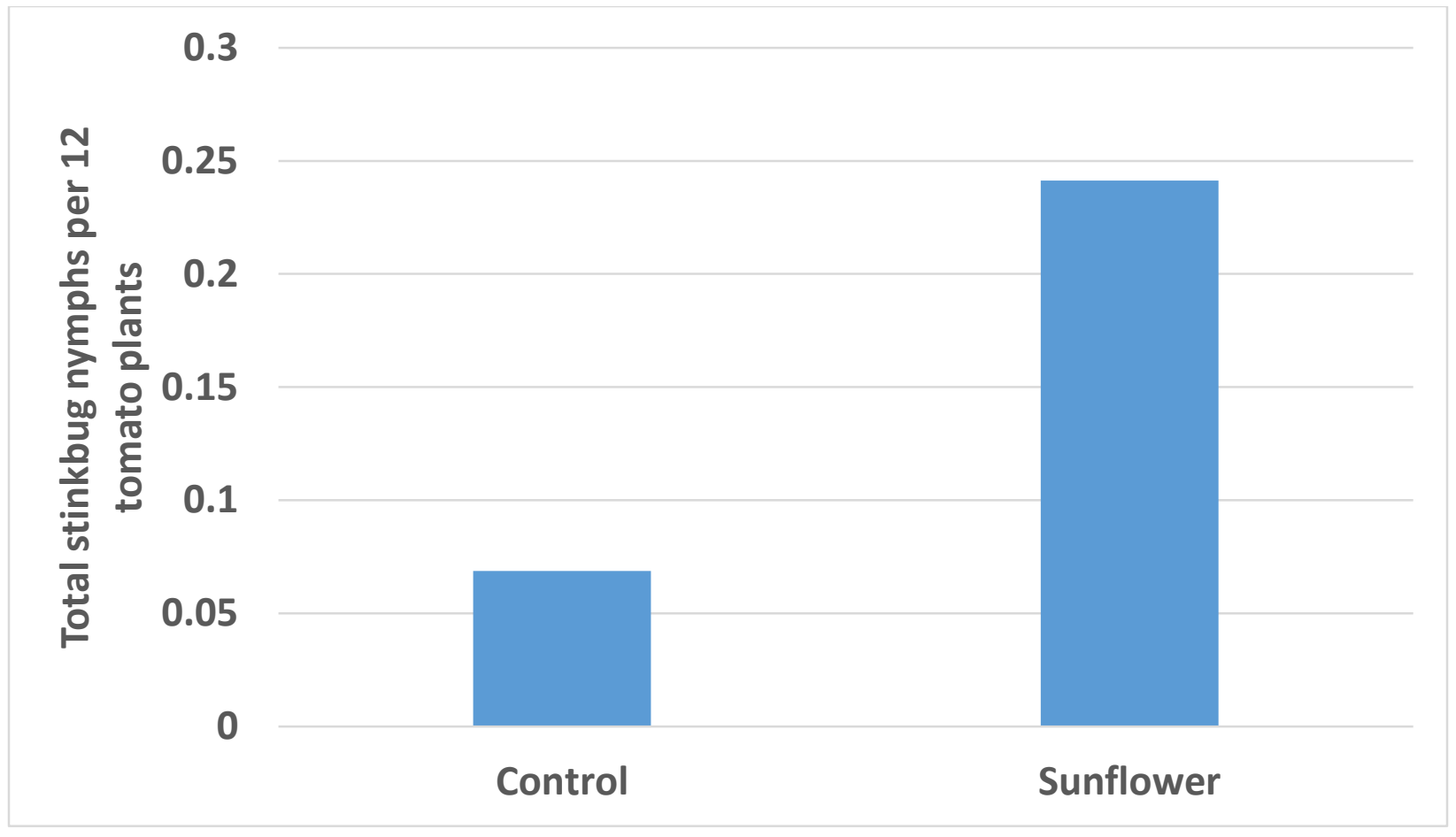

Fig. 1.7 Average total stink bug nymphs per tomato plant in 2013 and 2014 using data with nymphs hatched from a single egg mass in 2013 removed from analysis. Comparison made using a Wilcoxon signed-rank test $(P=0.96, n=29 z=0.053)$. 


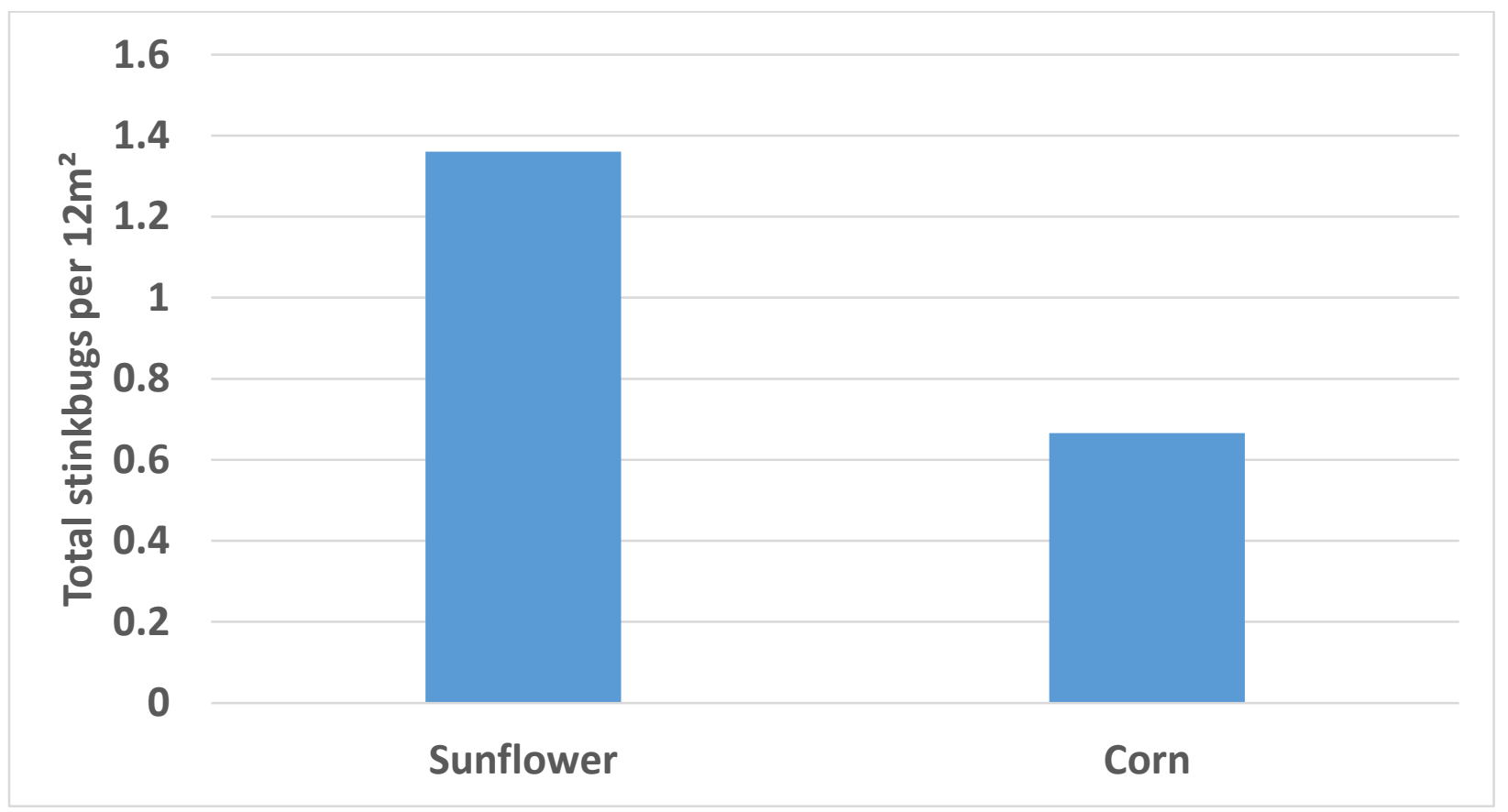

Fig. 1.8. Total stink bugs (adults and nymphs) in two trap crops in 2013. Comparison made using a Wilcoxon signed-rank test $(P=0.67, z=0.41)$. $H$. halys accounted for $88 \%$ of total stink bugs found in corn $(n=12)$ and $100 \%$ of total stink bugs found in sunflowers $(n=14)$. 


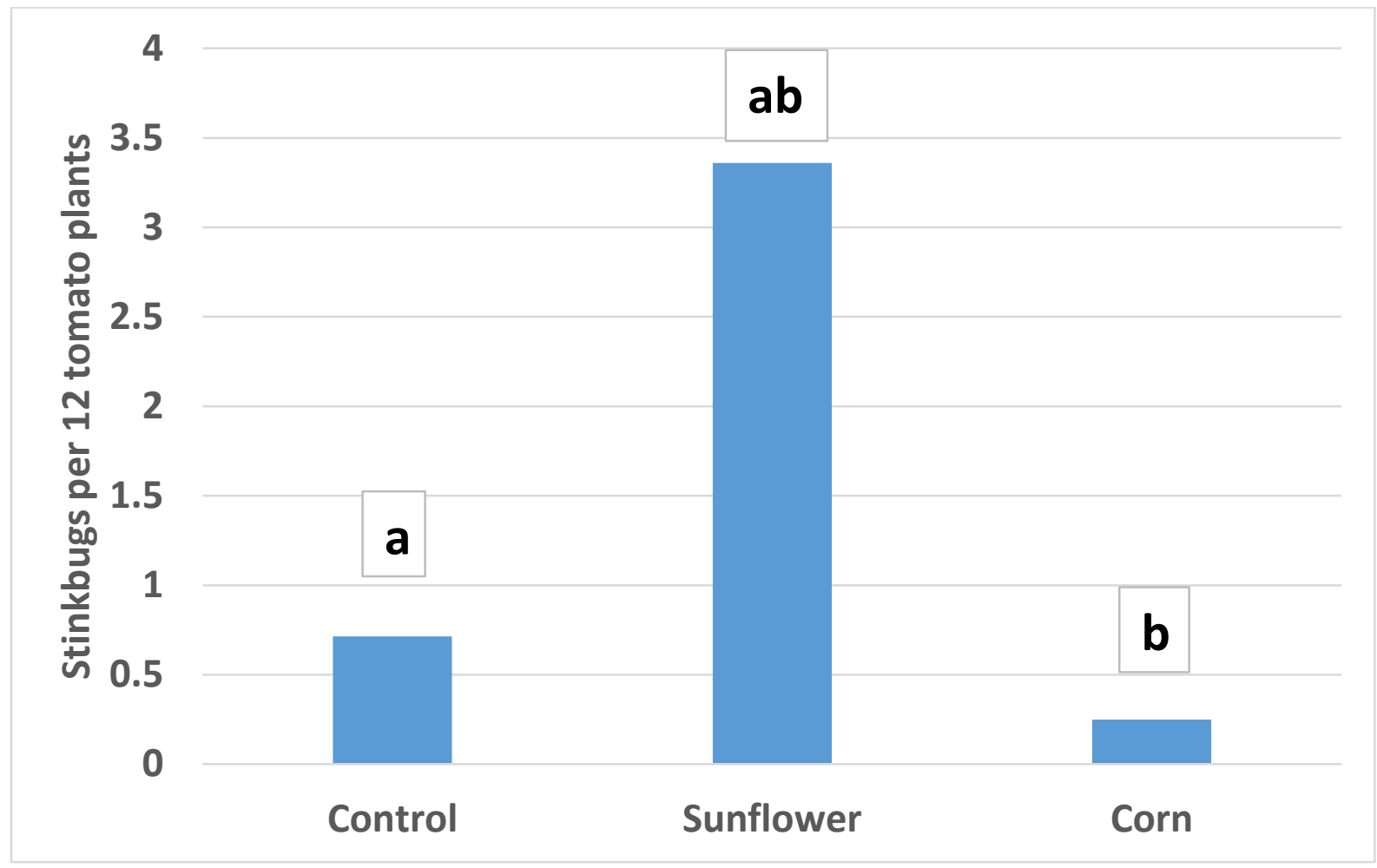

Fig 1.9. Average total stink bugs (all stages of $H$. halys and other spp.) found per 12 tomato plants per sampling period in 2013 in control plots $(n=14$, stdev. $=0.84)$ and plots with corn ( $n=12$, stdev.=7.99) and sunflower ( $n=14$ stdev.=1.72) trap crops. The high count of nymphs on tomatoes with sunflower trap crop resulted from a single egg mass, thus differences among treatments were not significant, despite the much higher mean. Comparison made using the Tukey-Kramer method $(P<0.10)$. 


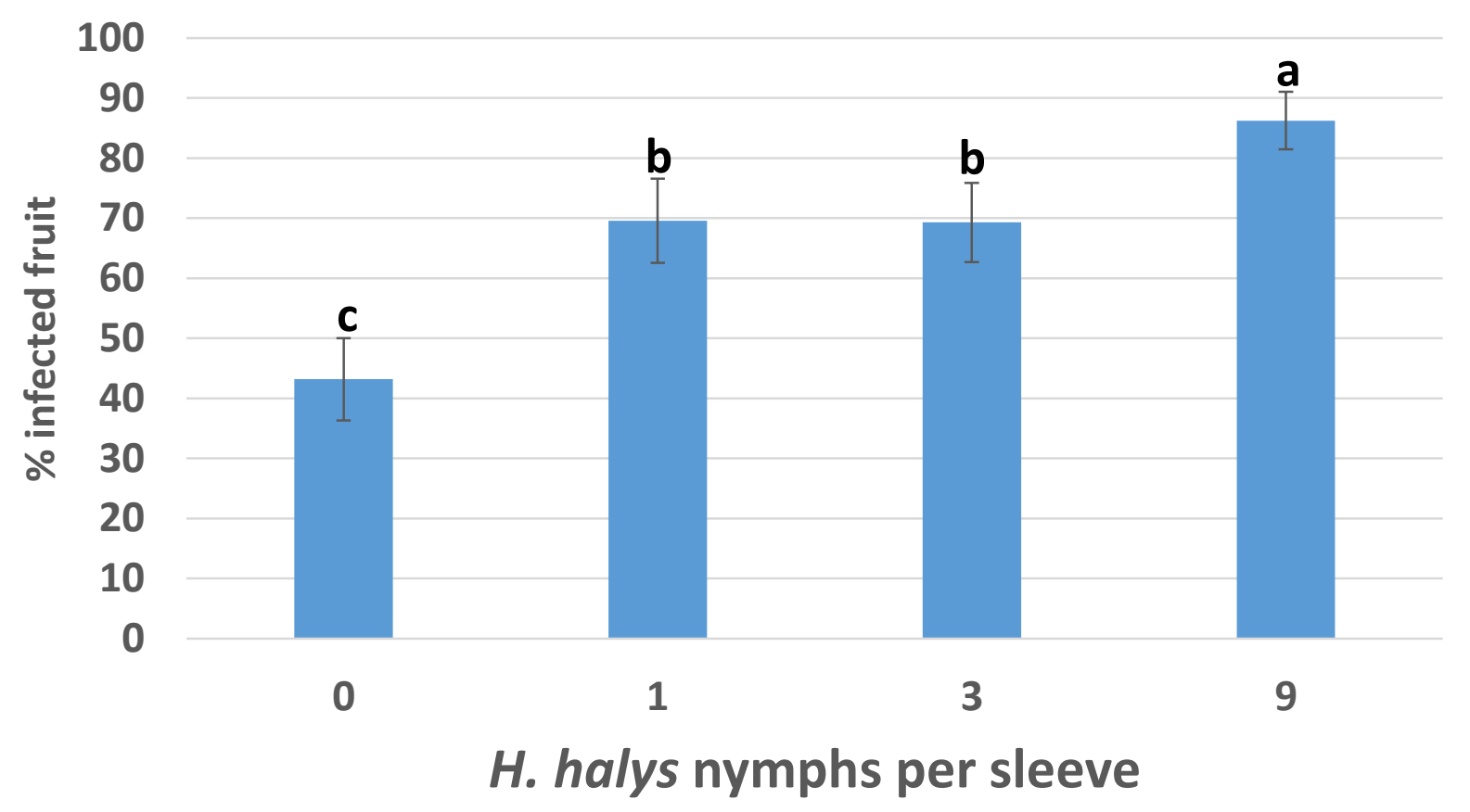

Fig 2.1. Effect of number of $H$. halys nymphs on Anthracnose incidence in the sleeve trial. Error bars represent standard error means. Means with the same letter do not differ according to Poisson Proc GENMOD Regression analysis $(P<0.05, n=12)$. 
A

B C

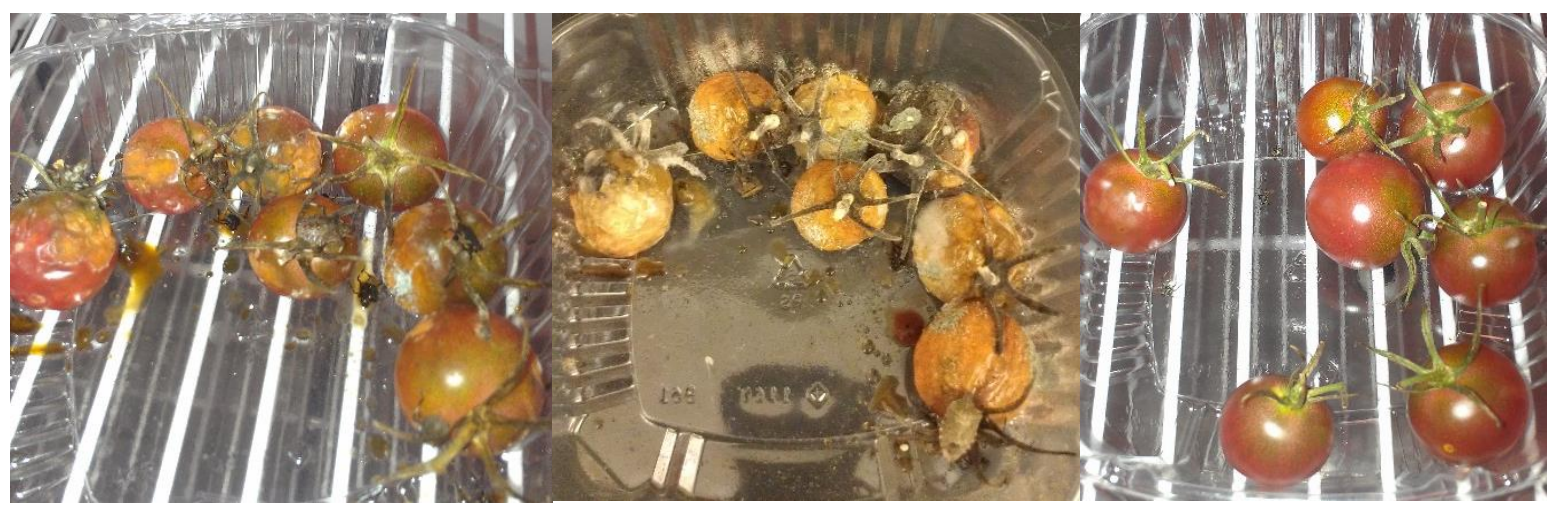

D

$\mathbf{E}$

$\mathbf{F}$

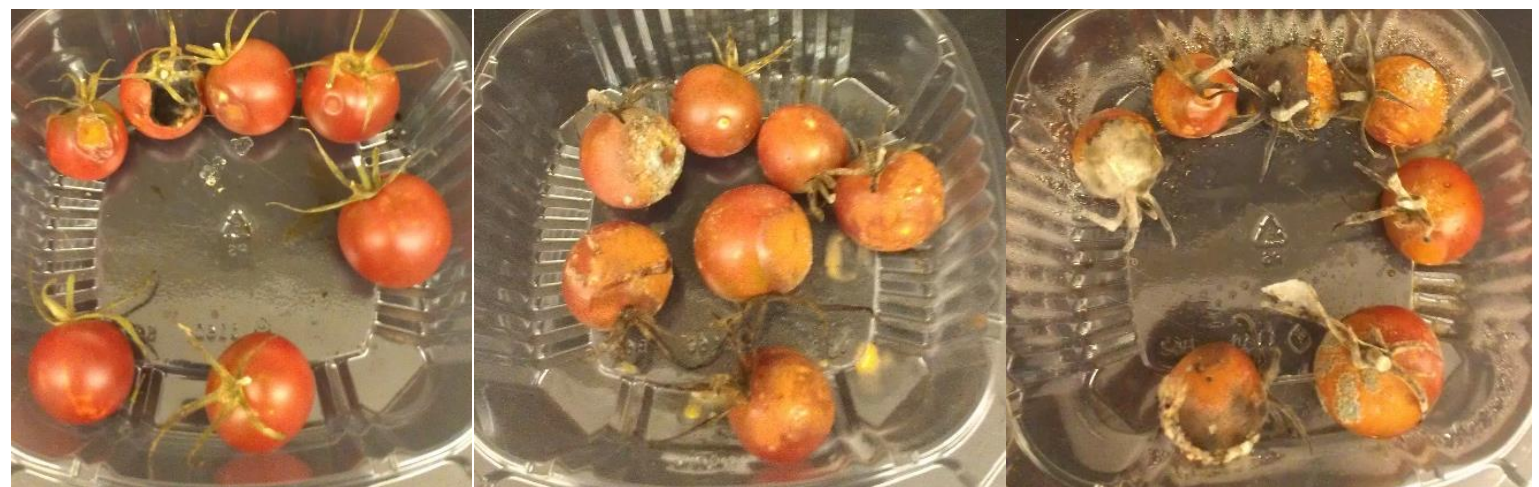

G

H

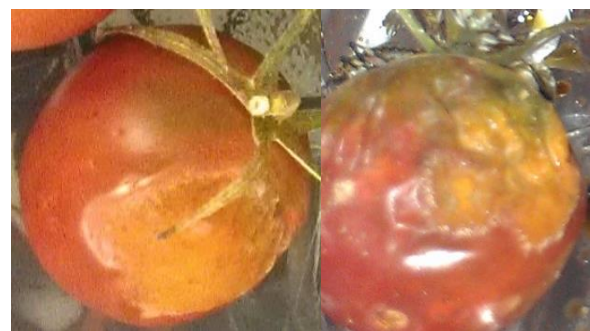

Fig 2.2. Tomatoes in different treatments of the incubator trial. A-B Treatment three (stink bugs with inoculum) at 10 and 21 days C Colletotrichum Inoculum only treatment at 10 days D-F Treatment 5 (stinkbug wounding plus delayed spray) at 10,17, and 21 days respectively G-H Close up visual of anthracnose lesions caused by WV12. Photo $\mathbf{G}$ is a picture of the a tomato fruit with inoculum only $(\mathrm{IO})$ as a treatment, photo $\mathbf{H}$ shows a tomato with stink bugs plus inoculum (SBI) as a treatment. 


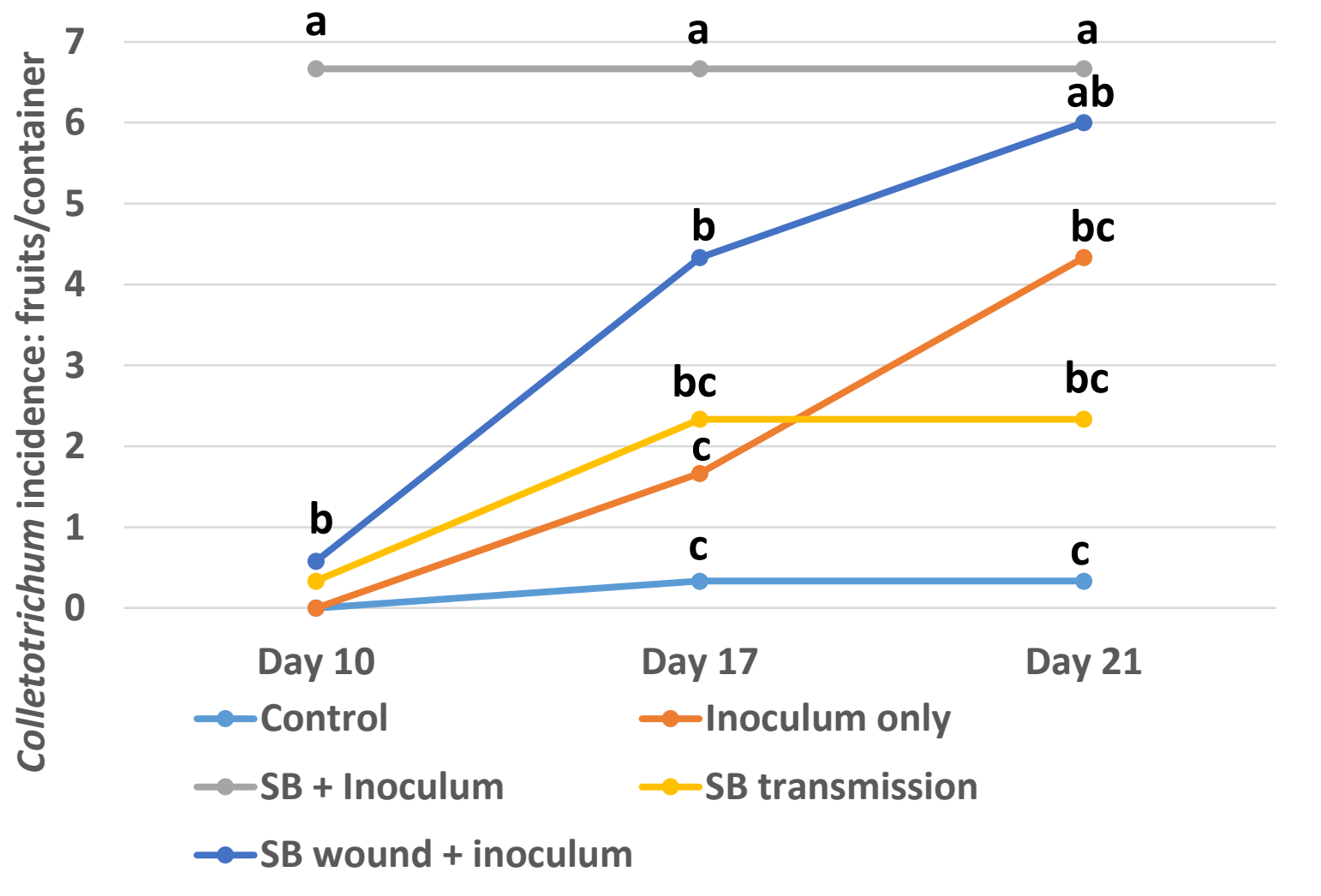

Fig 2.3. Anthracnose disease incidence in the incubator trial Letters within the same day represent differences found using nonparametric comparisons via the Wilcoxon Method $(P<0.077, n=3)$. 


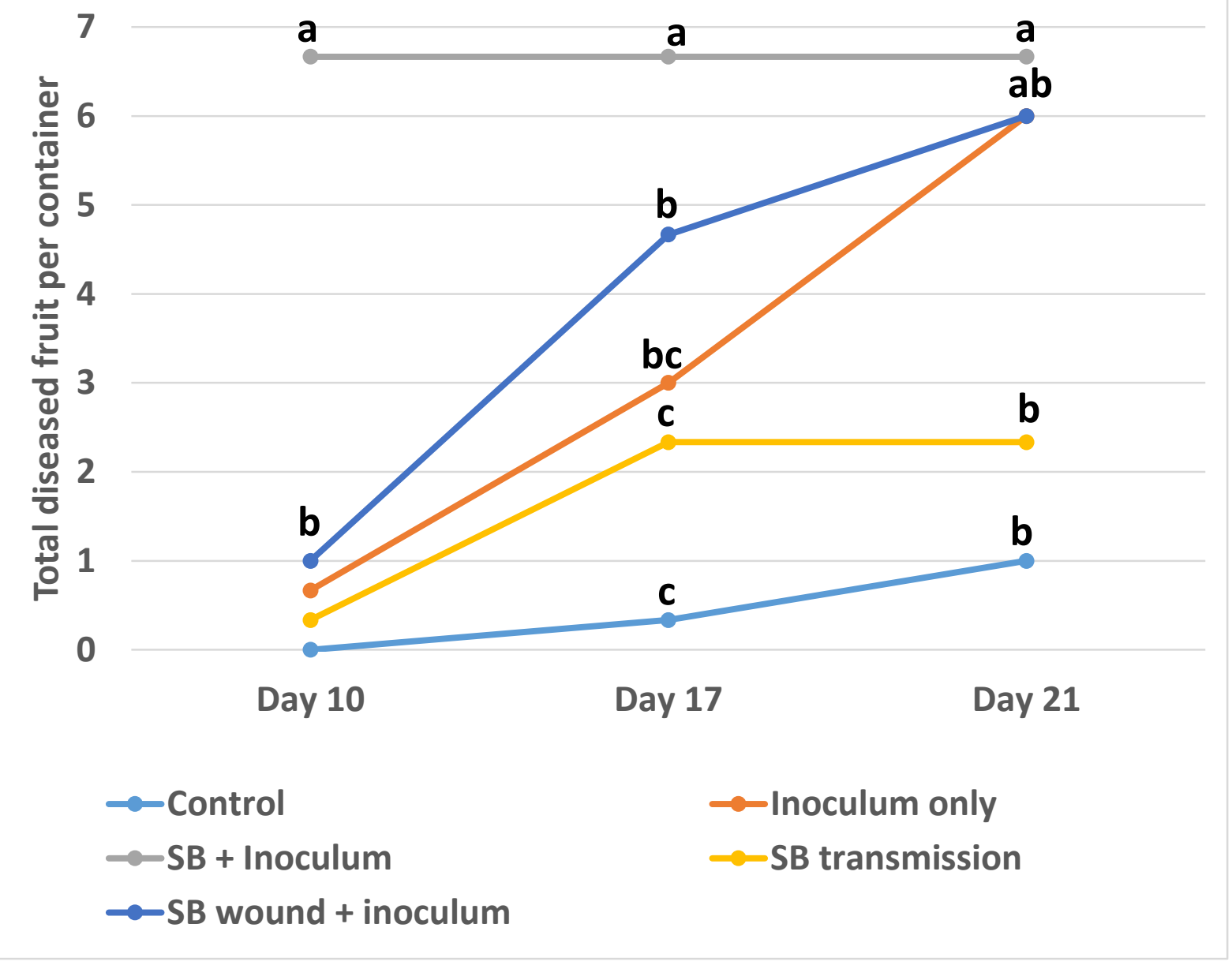

Fig. 2.4. Total diseased fruit per container in the incubator trial Letters within the same day represent differences found using nonparametric comparisons via the Wilcoxon Method $(P<0.077, n=3)$. 


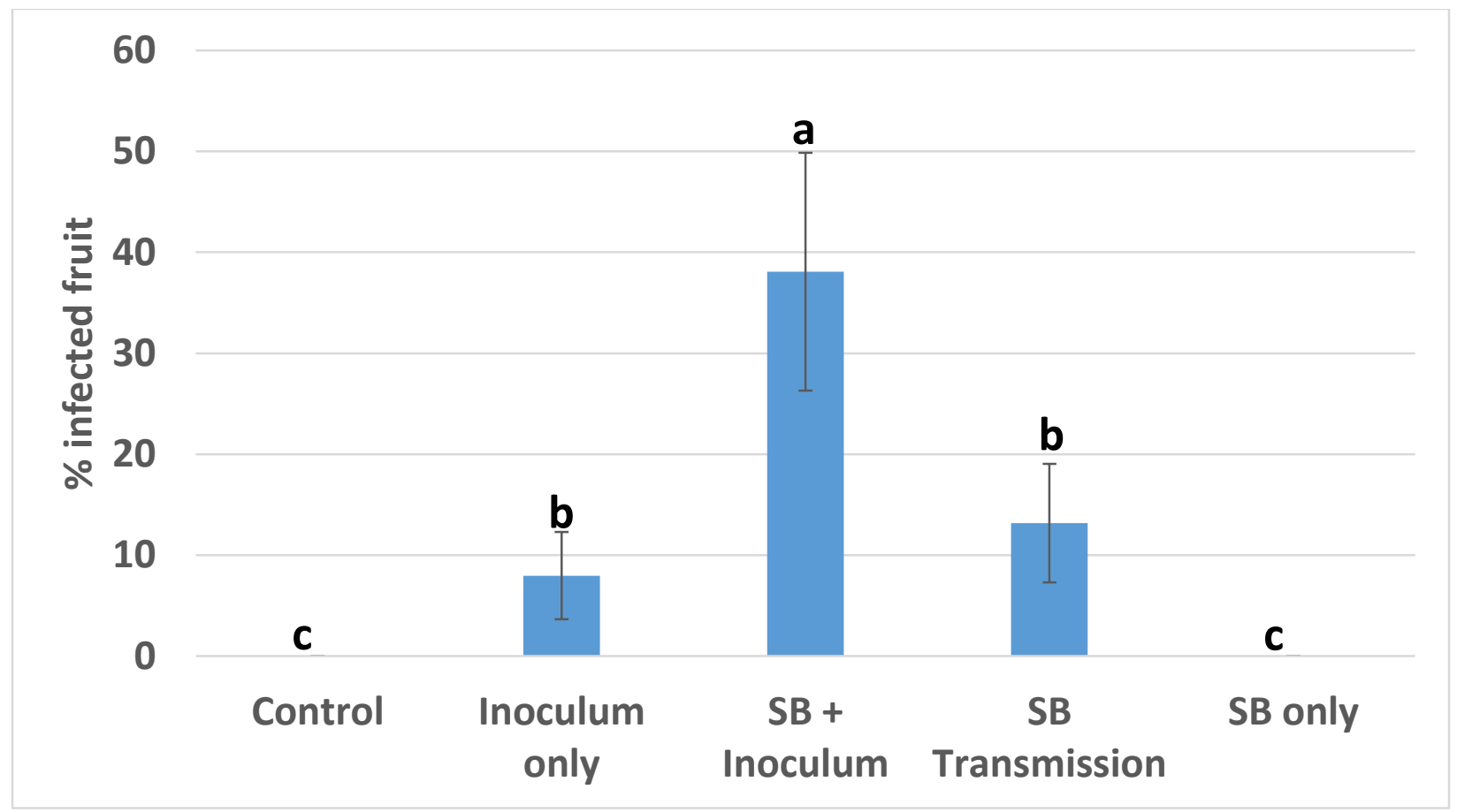

Fig 2.5. Colletotrichum incidence in the greenhouse trial. Error bars represent standard error. Figure represents means from two experiments. Stink bug + Inoculum resulted in the highest percentage of fruits with anthracnose $(P<0.05, n=4)$. Differences between SB only and treatments with inoculum added were less significant but still present $(P<0.10, n=4)$. $Z$ value separating $\mathrm{SBI}$ from SBT is 1.70 . Z value separating $\mathrm{IO}$ from $\mathrm{C}$ is 1.96 


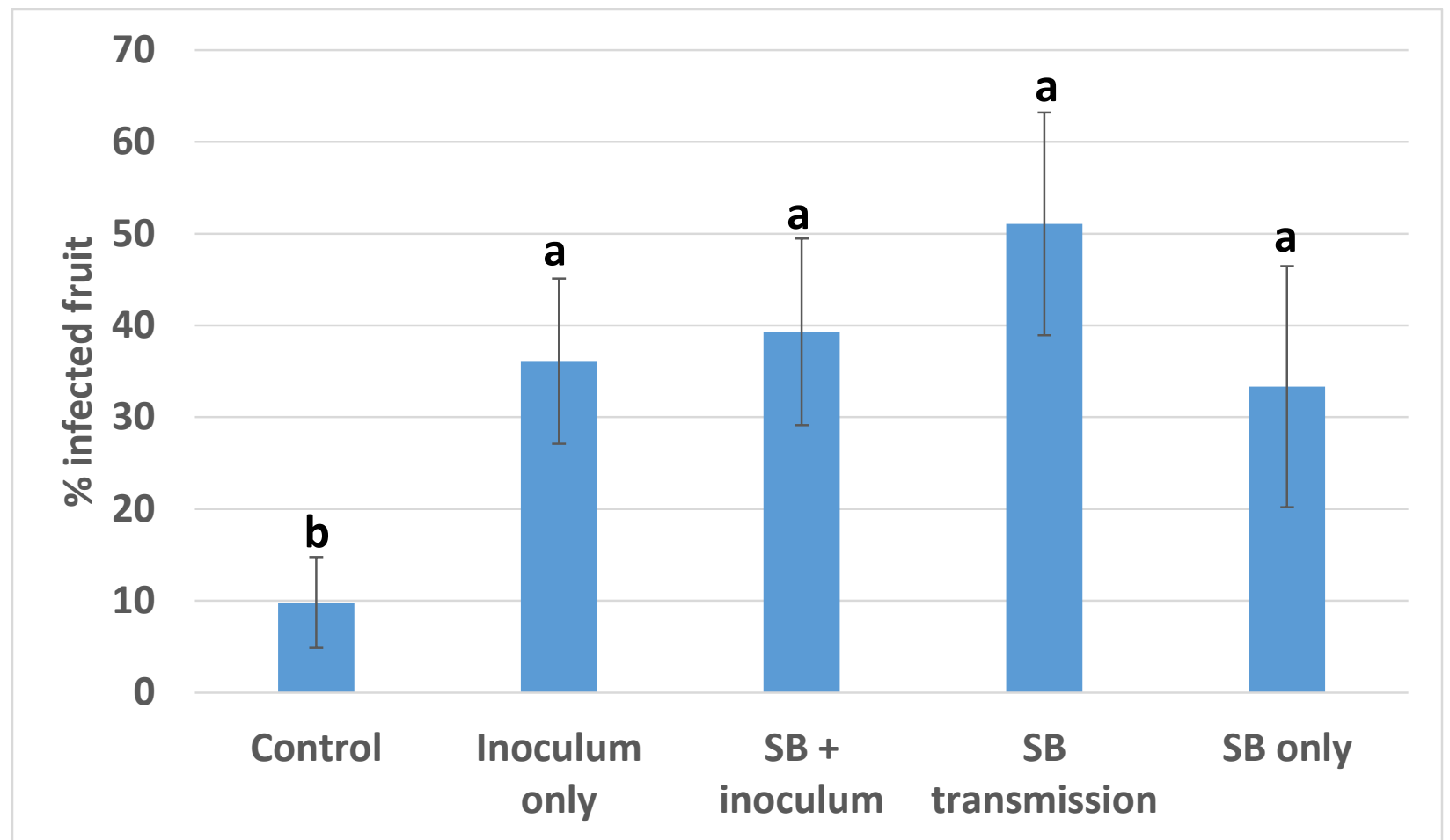

Fig 2.6. Percentage of total diseased fruit infected by a soft rot pathogen in the Greenhouse Trial. Error bars represent standard error. Treatments with the same letter do not differ according to the nonparametric Wilcoxon Method $(P<0.10, n=4)$. $Z$ value separating means of $\mathrm{SBO}$ and $\mathrm{C}$ is 0.241 . 


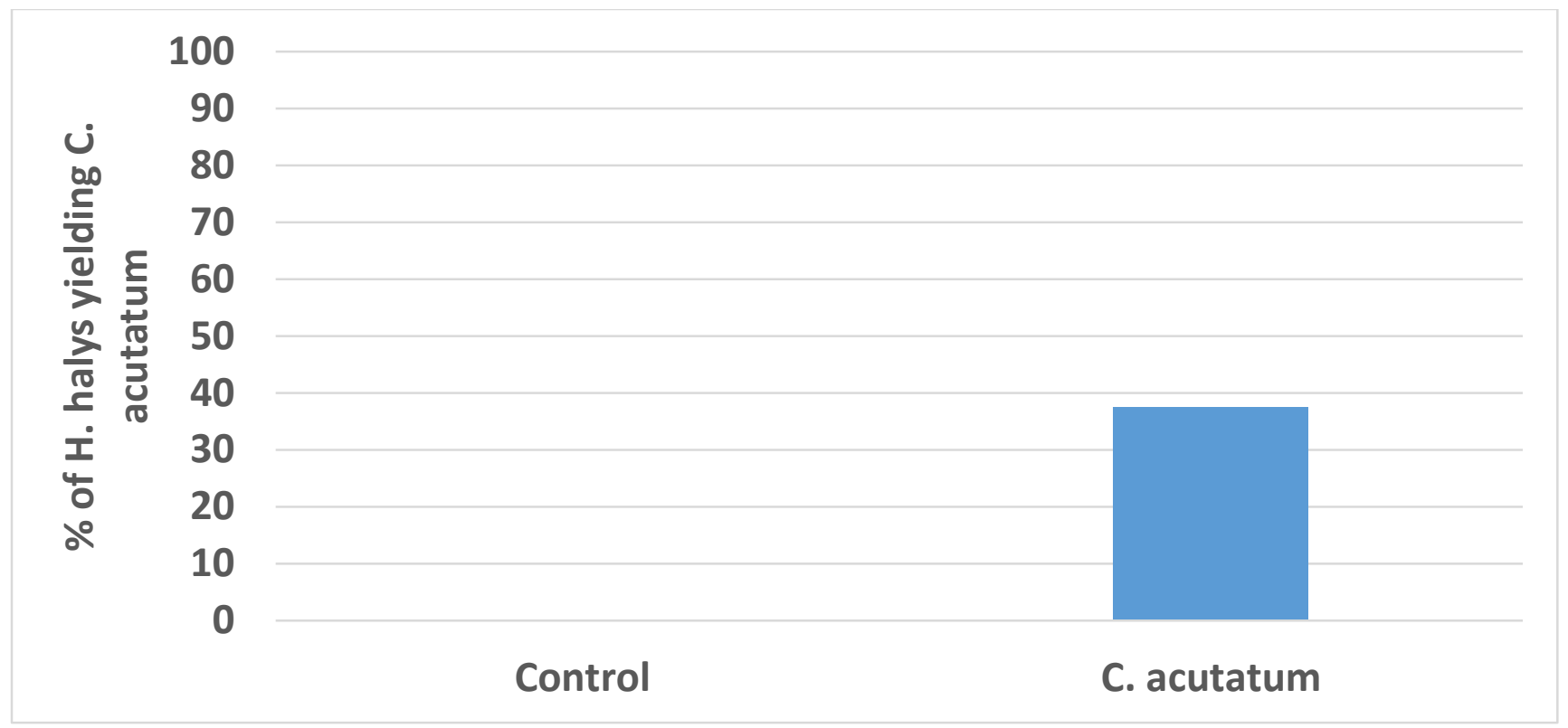

Fig. 2.7. Percentage of $H$. halys individuals that yielded viable $C$. acutatum cultures in the fungal isolation study. Of insects feeding on infected fruit, $37.5 \%$ yielded a viable culture from either the leg, stylet, or both. No controls yielded a Colletotrichum culture of any kind. Treatments differed according to the nonparametric Wilcoxon test $(P=0.032, n=8, z=2.14)$. 


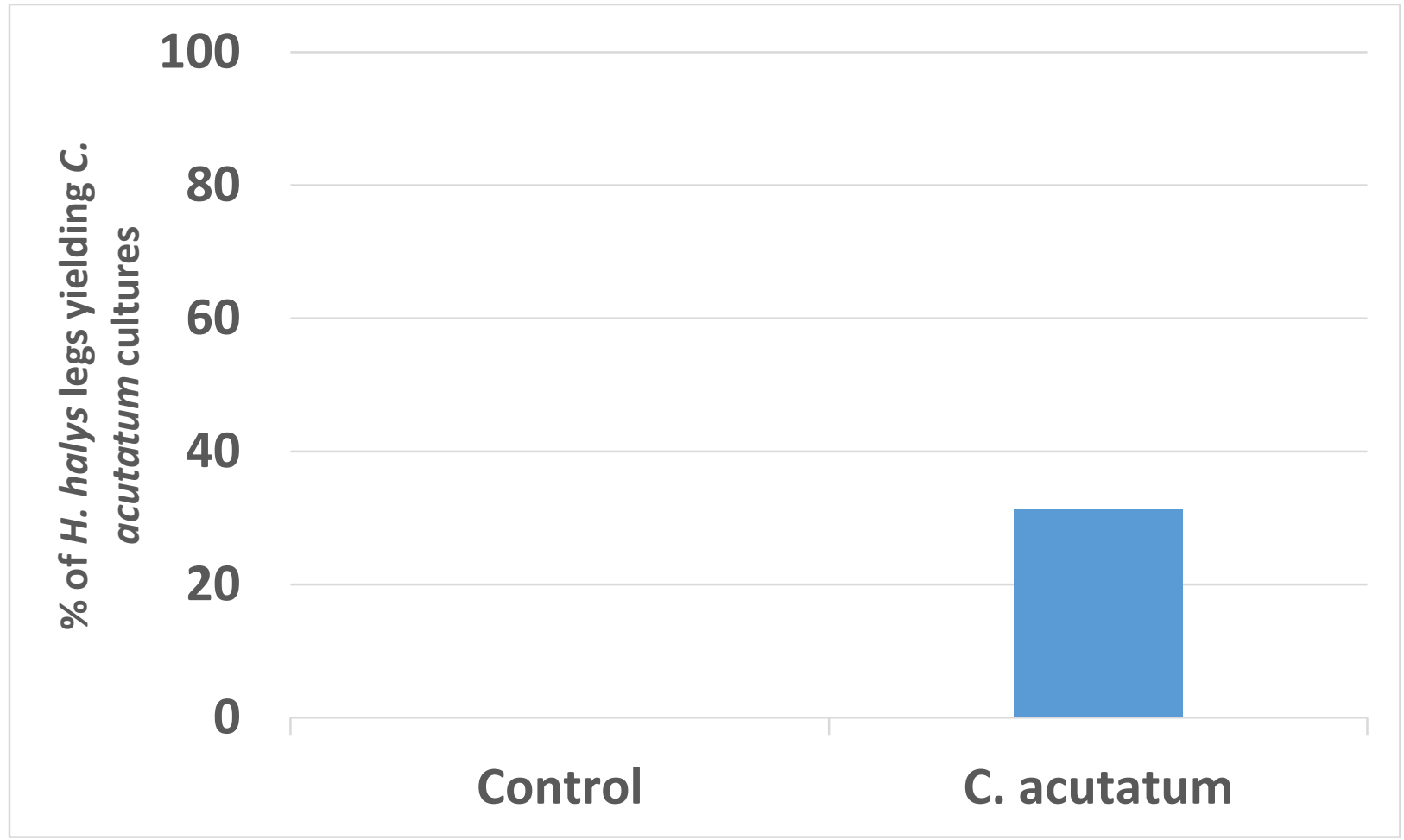

Fig. 2.8. Percentage of $H$. halys legs that yielded viable $C$. acutatum cultures. Of legs from insects feeding on infected tomatoes, $31.3 \%$ yielded a viable $C$. acutatum culture. One leg per insect was cultured. $(P=0.064, n=8, z=1.77)$. 


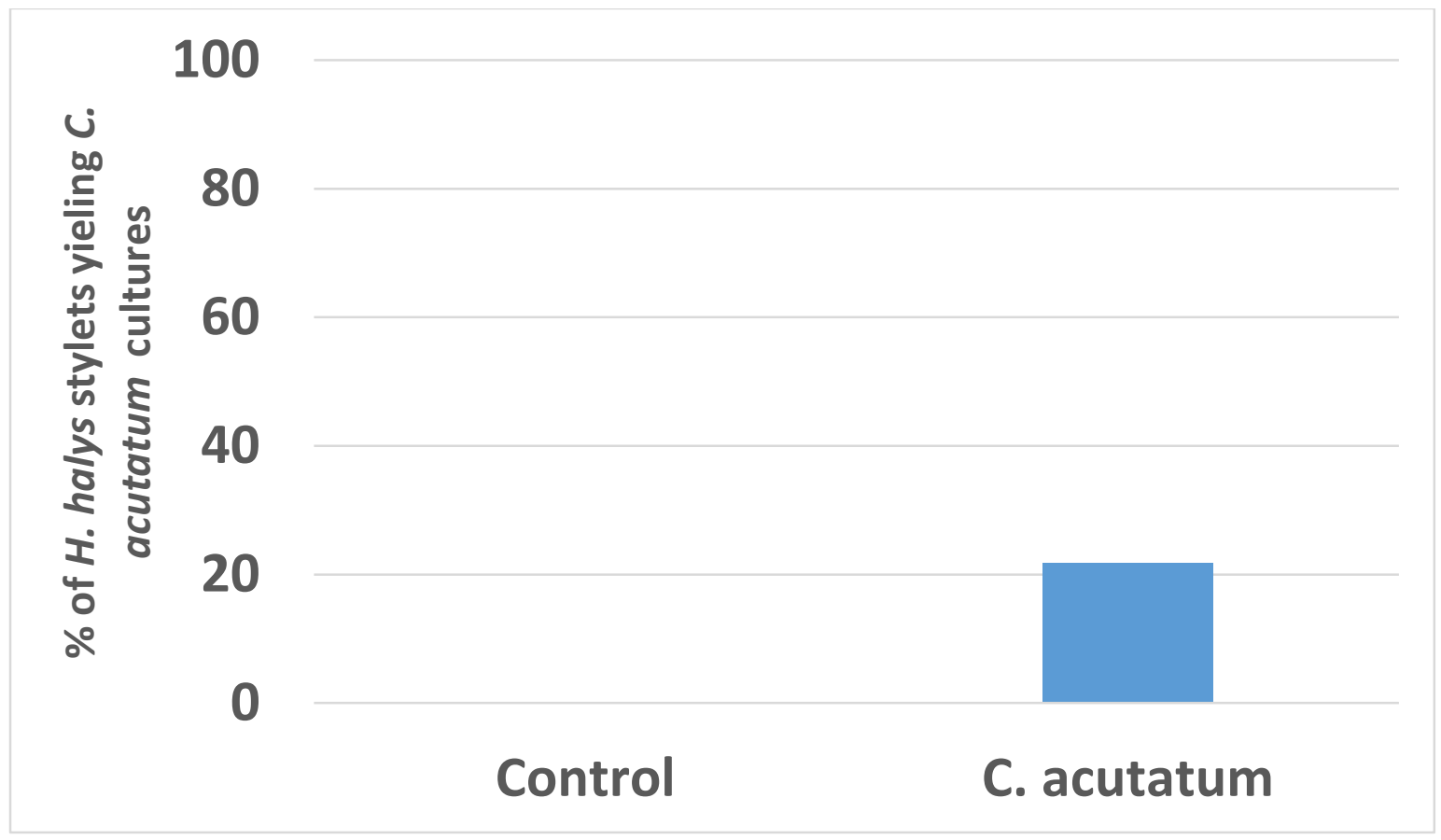

Fig. 2.9. Percentage of $H$. halys stylets that yielded viable $C$. acutatum cultures. Of stylets from insects feeding on infected tomatoes, $21.8 \%$ yielded a viable $C$. acutatum culture. $(P=0.076, n=8, z=1.78)$. 


\section{Tables}

Table 1.1 Non-parametric Spearman's correlation analysis of bacterial soft rot and stylet feeding scars on sunflower and control treatments across both seasons. Individual tomato fruits were experimental units used for analysis.

\begin{tabular}{lllll}
\hline Week Harvested & $\begin{array}{l}\text { Soft Rot } \\
\text { Spearman } \rho\end{array}$ & $\begin{array}{l}\text { Soft Rot } \\
\text { Prob }>|\rho|\end{array}$ & $\begin{array}{l}\text { Colletotrichum } \\
\text { Spearman } \rho\end{array}$ & $\begin{array}{l}\text { Colletotrichum } \\
\text { Prob }>|\rho|\end{array}$ \\
\hline 1 & 0.129 & 0.408 & -0.0238 & 0.880 \\
2 & 0.123 & 0.077 & 0.419 & $<0.0001$ \\
3 & -0.006 & 0.898 & 0.189 & 0.0001 \\
4 & 0.078 & 0.051 & 0.169 & $<0.0001$ \\
5 & 0.153 & 0.0001 & 0.268 & $<0.0001$ \\
6 & 0.116 & 0.0063 & 0.307 & $<0.0001$ \\
Total Average & 0.0855 & $<0.0001$ & 0.239 & $<0.0001$ \\
\hline
\end{tabular}


Table 1.2 Monthly rainfall data for the 2013 and 2014 growing seasons

\begin{tabular}{llll}
\hline Month & 2013 & 2014 & Average \\
& Rainfall $(\mathrm{mm})$ & Rainfall $(\mathrm{mm})$ & Rainfall $(\mathrm{mm})$ \\
\hline May & 98 & 115 & 117 \\
June & 121 & 115 & 104 \\
July & 169 & 138 & 117 \\
August & 130 & 128 & 91 \\
September & 51 & 59 & 82 \\
\hline
\end{tabular}


Table 1.3. Non-parametric correlation of disease parameters across treatments Sunflower and Control in 2013 and 2014 growing seasons ( $n=2459)$.

\begin{tabular}{llcr}
\hline Nonparametric: Spearman's $\rho$ & & \\
Variable & by Variable & Spearman $\rho$ & $<0.0001$ \\
\hline feeding scars & Colletotrichum & 0.2385 & 0.2164 \\
soft rot & Colletotrichum & -0.0250 & $<0.0001$ \\
soft rot & feeding scars & 0.0855 & $<0.0001$ \\
black spotting & Colletotrichum & -0.0879 & 0.2987 \\
Black spotting & Feeding Scars & -.021 & $<0.0001$ \\
Black spotting & Soft Rot & -0.0989 & 0.316 \\
Mold & Colletotrichum & 0.0203 & 0.0562 \\
Mold & Feeding Scars & -0.0385 & $<0.0001$ \\
Mold & soft rot & 0.0968 & 0.0545 \\
Mold & black spotting & -0.0388 & $<0.0001$ \\
Cracking & Colletotrichum & -0.3106 & $<0.0001$ \\
Cracking & feeding scars & -0.1745 & $<0.0001$ \\
Cracking & soft rot & -0.1191 & 0.0007 \\
Cracking & black spotting & -0.0687 & $<0.0001$ \\
Cracking & mold & 0.1651 &
\end{tabular}


Table 2.1 Two way analysis of variance of treatment effects on Colletotrichum incidence.

\begin{tabular}{llll}
\hline Effect & d.f. & Means Square & F value \\
\hline Number of insects & 3 & 0.3792 & 7.827 \\
Days in sleeve & 1 & 0.1299 & 2.6791 \\
Days in sleeve $x$ & 3 & 0.0258 & 0.5323 \\
number of insects & & & \\
\hline Error Mean Square & 4 & 0.0485 & 0.0485 \\
\hline
\end{tabular}




\section{References}

Agrios, G. N. 1997. Plant Pathology, 4th ed. Academic Press Limited, San Diego, CA.

Altieri, M. A. 1999. The ecological role of biodiversity in agroecosystems. Agriculture, Ecosys., \& Env. 74 (1-3):19-31.

Anil, L., Park, J., Phipps, R. H., and Miller, F. A. 1998. Temperate intercropping of cereals for forage: a review of the potential for growth and utilization with particular reference to the UK. Grass and For. Sci. 53:301-317.

Ariyawansa, H.A., Hawksworth, D.L., Hyde, K.D., Jones, E.B.G., Marachikumbura, S.S.N., Manamgoda, D., Thambugala, K.M., Udayanga, D., Camporesi, E., Daranagama, A., Jayawardena, R., Liu, J.K., McKenzie, E.H.C., Phookamsak, R., Senanayake, I.C., Shivas, R.G., Tian, Q., and Xu, J.C. 2014. Epitypification and neotypification: guidelines with appropriate and inappropriate examples. Fungal Div. 69:57-91.

Ashby, S.F., and Nowell, W. 1926. The fungi of stigmatomycosis. Ann. Botany (London) 40:69-83

Bailey, J.A. and Jeger, M.J. 1992. Colletotrichum. Biology Pathology and Control. (Bailey JA, Jeger MJ eds). CABI Wallingford, UK 88-120.

Barnett, H.L. and Hunter. B.B. (1972). Illustrated genera of imperfect fungi. $3^{\text {rd }}$ ed. Burgess Publishing Company. Minneapolis, MN.

Ben-Daniel, B., Bar-Zvi, D., and Tsror, L. 2009. An improved large-scale screening method for assessment of Colletotrichum coccodes aggressiveness using mature green tomatoes. Plant Pathol. 58(3):497-503.

Bergman, E.J. and Raupp, M.J. 2014. Efficacies of common ready to use insecticides against Halyomorpha halys (Hemiptera: Pentatomidae). Flor. Entomol. 97(2):791-800.

Byrne, J.M., Hausbeck, M.K., and Hammerschmidt, R. 1997. Conidial germination and appressorium formation of Colletotrichum coccodes on tomato foliage. Plant Dis. 81:715-718.

Byrne, J.M., Hausbeck, M.K., Meloche, C., and Jarosz, A.M. 1998. Influence of dew period and temperature on foliar infection of greenhouse-grown tomato by Colletotrichum coccodes. Plant Dis. 82:639-641.

Brozek and Hreczek 2004. Internal structure of the mouthparts of true bugs (Hemiptera: Heteroptera). Polish J. of Entomol. 73:79-106. 
Caldwell, B. Sideman, E., Seaman, A., Shelton, A., and Smart, A. 2013 Resource Guide for Organic Insect and Disease Management. $2^{\text {nd }}$ ed. New York State Agricultural Experiment Station. Geneva, NY Published by Cornell University.

Cano, J. Guarro, J., and Gene, J. 2004. Molecular and morphological identification of Colletotrichum species of clinical interest. J. of Clin. Microbiol. 42(6):2450-2454.

Cannon, P., Damm, U., Crous, and P., Woudenberg, J. 2012. The Colletotrichum acutatum complex. Stud. In Mcyol. 73(1):37-113.

Corda, A.C.I. 1831. Die Pilze Deutschlands (ed. J. Sturm). Deutschlands Flora, 3. Abtheilung 3:1144.

Corn, L.M., Buck, E.U., Rawson, J., Seagarra, A., and Fischer, E. 2002 Invasive and Non-Native Species: Background and Issues for Congress. Resources, Science, and Industry Division (CRS): RL30123

Cullen, E.M. and Zalom, F.G. 2000. Phenology-based field monitoring for consperse stink bug (Hemiptera: Pentatomidae) in processing tomatoes. Env. Entomol. 29(3): 560-567

Damm, U. Cannon, P., Woudenberg, J., and Crous, J. 2012 The Colletotrichum acutatum species complex. Stud. Mycol. 73(1):37-113.

De Sahagun, F.B. 1969. Historia General de las Cosas de Nueva Espana. Mexico, DF: Editor Porrua.

Dhandapani, N., Shelkar, U.R., and Murugan, M. 2003. Bio-intensive pest management (BIPM) in major vegetable crops: An Indian perspective. Food, Agric. \& Env. 1(2):333-339.

Diao, Y.Z., Zhang, C., Lin, D., and Liu, X.L. 2014. First report of Colletotrichum truncatum causing anthracnose of tomato in China. Plant Dis. 98(5): 687-688.

Dillard H. R. 1986. Control of fungal and bacterial diseases of processing tomato with foliar sprays, 1985. Fungic. Nematic. Tests 41:64.

Dillard, H.R. 1988a. Effect of temperature, wetness duration, and inoculum density on infection and lesion development of Colletotrichum coccodes on tomato fruit. Phytopathology 79:1063-1066.

Dillard, H.R. 1988b. Influence of temperature, pH, osmotic potential, and fungicide sensitivity on germination of conidia and growth from sclerotia of Colletotrichum coccode in vitro. Phytopathology. 78:1357-1361. 
Dillard, H.R. and Cobb, A.C. 1998. Survival of Colletotrichum coccodes in infected tomato tissue and in soil. Plant Dis. 82:235-238.

Dively, G., Patton, T., and Hooks, C. 2012. Summary of Brown Marmorated Stink Bug Infestations in Maryland Crops. Unpublished data, University of Maryland College Park.

Godfrey, L. and Leigh, T. 1994. Alfalfa harvest strategy effect on lygus bug (Hemiptera, Miridae) and insect predator population density-implications for use as trap crop in cotton. Env. Entomol. 23:1106-1118.

Francis, C.A. 1986. Multiple Cropping Systems, MacMillan, New York 383 pp.

Garibaldi, A., Baudino, M., Minuto, A., and Gullino, M. 2008. Effectiveness of fumigants and grafting against tomato brown root rot caused by Colletotrichum coccodes. Phytoparasitica 36(5):483-488.

Gutierrez, L., Chapin, Y., and Gardner, B. 2006. Distribution and fungicide sensitivity of fungal pathogens causing anthracnose-like lesions on tomatoes grown in Ohio. Plant Dis. 90(4):397-403.

Haye, T., Abdallah, S., Gariepy, T., and Wyniger, D. 2014. Phenology, life table analysis and temperature requirements of the invasive Brown Marmorated Stink Bug Halyomorpha halys, in Europe. J. of Pest Sci. 87:407-418.

Hoebeke, E.R., and Carter, M.E. 2003. Halyomorpha halys: a new polyphagous plant pest from Asia newly detected in North America. Proceedings of the Entomological Society of Wash. 105(1):225-237.

Hoffman, M.P. Wilson, L.T., and Zalom, F.G. 1987. Control of stink bugs in tomatoes. Calif. Agric. 41(5):4-6.

Hyde, K.D., Cai, L., McKenzie, E.H.C., Yang, Y.L., Zhang, J.Z., and Prihastuti, H. 2009. Colletotrichum: a catalogue of confusion. Fungal Div. 39:1-17.

Inderbitzin, P., Davis, R. M., Bostock, R. M., \& Subbarao, K. V. (2011). The ascomycete Verticillium longisporum is a hybrid and a plant pathogen with an expanded host range. PLoS One, 6(3), e18260.

Jelev, Z.J., Bobey, S.G., Minz, D., Maymon, M., and Freeman, S. 2008. First report of anthracnose fruit rot caused by Colletotrichum acuctatum on pepper and tomato in Bulgaria. Plant Dis. 92(1):172.

Kamanyire R. and Karalliedde, L. 2004. Organophosphate toxicity and occupational exposure. Occupational Medicine. 54:2. 
Kimura, S., Tokumaru, S., and Kuge, K., 2008a. Eremothecium ashbyi causes soybean yeast spot and is associated with stink bug, Riptotrus clavus. J. Gen. Plant Pathol. 74:275-280.

Kimura, S., Tokumaru, S., and Kuge, K. 2008b. Mode of transmission and morphological structures of two Eremothecium species between Riptortus pedestris and soybean. J. Gen. Plant Pathol. 74:390-394.

Koureas, M., Tsakalof, A., Tsatsakis, A., and Hadjichristodoulou, C. 2012. Systemic review of biomonitoring studies to determine association between exposure to organophosphorus and pyrethroid insecticides in human health outcomes. Toxicology Letters. 210:155-168.

Lee, D.H., Wright, S.E., Boiteau, G., Vincent, C. and Leskey, T.C. 2013a. Effectiveness of Glues for Harmonic Radar Tag Attachment onHalyomorpha halys (Hemiptera: Pentatomidae) and Their Impact on Adult Survivorship and Mobility. Env. Entomol. 42(3):515-523.

Lee, D.H. Wright,S.E., and Leskey T.C. 2013b. Impact of insecticide residue exposure on the invasive pest Halymorpha halys (Hemiptera: Pentatomidae): Analysis of adult mobility. J. Econ. Entomol. 106(1):150-158.

Lee, D.H., Cullum, J.P., Anderson, J.L., Daugherty, J.L., Beckett, L.M., and Leskey, T.C. $2014 a$. Characterization of overwintering sites of the invasive brown marmorated stink bug in natural landscapes using human surveyors and detector canines. PLOS one 9(4):37-47.

Lee, D.H., Short, B., Nielsen, A.L., and Leskey, T.L. 2014b. Impact of organic insecticides on the survivorship and mobility of Halyomorpha halys (Stal) (Hemiptera Pentatomidae) in the Laboratory. Flor. Entomol. 97(2):414-421.

Leskey, T.C., Hamilton, G.C., Nielsen, A.L., Polk, D.F., Rodriquez-Saona, C., Christopher, B., Herbert, D.A., Kuhar, T.P., Pfeifer, D. Dively, G.P. Hooks, C., Raupp, M.J., Shrewsbury, P.M., Krawczyk, G., Shearer, P.W., Whalen, J., Koplinka-Loeher, C., Myers, E., Inkley, D., Hoelmer, K.A., Lee, D.H., and Wright, S.E. 2012a. Pest status of the Brown Marmorated Stink Bug (Halyomorpha halys) in the USA. Outlooks on Pest Management. 23:218-226

Leskey, T.C., Short, B.D., Butler, B.R., Wright, S.E. 2012b. Impact of the invasive Brown Marmorated Stink Bugs in orchards in the United States: Case studies of commercial management. Psyche: A J. Entomol. 2012: 14 pages.

Leskey, T.C., Wright, S.E., Short, B.D., and Khrimian, A. 2012c. Development of behaviorally based monitoring tools for the Brown Marmorated Stink Bug (Heteroptera Pentatomidae) in commercial tree fruit orchards. J. of Entomol. Sci. 47:76-85. 
Leskey, T.C., Lee, D.H., Short, B.D., and Wright, S.E. 2012d. Impact of insecticides on the invasive Halyomorpha halys(Hemiptera: Pentatomidae): analysis of insecticide lethality. J. Econ. Entomol. 105(5):1726-1735.

Liu, F. Hyde, K.D., and Cai, L. 2011. Neotypification of Colletotrichum coccodes, the causal agent of potato black dot disease and tomato anthracnose. Mycology. 2(4):248-254.

Luchi, N., Mancini, V., Feducci, M., Santini, A., and Capretti, P. 2012. Leptoglussus occidentalis and Diplodia pinea: a new insect-fungus association in Mediterranean forests. For. Pathol. 42(3):246-251.

Malezieux, E. 2012. Designing cropping systems from nature. Agron. Sustain. Dev. 32:15-29.

Medrano, E.G., Esquivel, J., Bell, A., Greene, J. Roberts, P., Bacheler, J., Marois, J., Wright, D., Nichols, R., and Lopez J. 2009. Potential for Nezara viridula(Hemiptera:Pentatomidae) to Transmit Bacterial and Fungal Pathogens into Cotton Bolls. Cur Microbiol. 59(4):405412.

Morris, P.F., Connolly, M.S., and St. Clair, D.A. 2000. Genetic diversity of Alternaria alternata isolated from tomato in California assessed using RAPDS. Mycol. Res. 104:286-292.

Mitchell, P.L. 2004. Heteroptera as vectors of plant pathogens. Neotrop. Entomol. 33(5):519-545.

Mukerji, K.G. 1968. Nematospora coryli. CMI Descriptions of Plant Pathogenic Fungi and Bacteria 184.

Nielsen, A.L., Shearer, P.W., and Hamilton, G.C. 2008. Toxicity of insecticides to Halyomorpha halys (Hemiptera: Pentatomidae) using glass-vial bioassays. J. Econ. Enomol. 101(4):1439-1442.

Nielsen, A.L. and Hamilton, G.C. 2009. Life history of the invasive species Halyomorpha halys in the Northeastern United States. Ann. of the Entomol. Soc. of America. 102:608-616.

Nielsen, A.L., Grieshop, M.J., and Gut, L. 2010. Brown marmorated stink bug: description, damage, monitoring and control considerations for Michigan's conditions. Fruit Crop Advisory Team Alert: current news articles for fruit production. Online 3/13/2011: http://www.ipmnews.msu.edu/fruit/Fruit/tabid/123/articleType/ArticleView/articleld/3 247/Br own-Marmorated-Stink-Bug. aspx.

Nielsen, A.L., Holmstrom, K., Hamilton, G.C., Cambridge, J., and Ingerson,-Mahar, J. 2013. Use fo Black Light Traps to Monitor the Abundance, Spread, and Flight Behavior of Halyomorpha halys (Hemiptera: Pentatomidae). J. Econ. Entomol. 106(3):1495-1502. 
Pair, S.D. 1997. Evaluation of systemically treated squash trap plants and attracticidal baits for early season control of striped and spotted cucumber beetles (Coleoptera: Chyrsomelidae) and squash bug (Hemiptera: Coreida) in cucurbit crops. J. Econ. Entomol. 90:1307-1314.

Pease, C.G. and Zalom, F.G. 2010. Influence of non-crop plants on stink bug (Hemiptera: Pentatomidae) and natural enemy abundance in tomatoes. J. Applied Entomol. 134(8):626-636.

Pedigo, L.P. and Rice, M.E. 2006. Entomology and Pest Management $5^{\text {th }}$ ed. Pearson Education Inc.

Piper, J.K. 1999. Growth and seed yield of three perennial grains within monocultures and mixed stands. Agriculture, Ecosystems, and Environment 68:1-11.

Sang, M.K. and Kim, K.D. 2011. Biocontrol activity and primed systemic resistance by compost water extracts against Anthracnoses of pepper and cucumber. Phytopathology. 101(6):732-740.

Sanogo, S. Stevenson, R.E., and Pennypacker, S.P. 2003. Appressorium Formation and Tomato Fruit Infection by Colletotrichum coccodes. Plant Dis. 87:336-340.

Sargent, C., Martinson, H., and Raupp, M. 2014. Traps and trap placement may affect location of brown marmorated stink bug (Hemiptera: Pentatomidae) and increase injury to tomato fruits in home gardens. Env. Entomol. 4(2):432.438.

Shelton, A.M., and Badenes-Perez, F.R. 2006. Concepts and applications of trap cropping in pest management. Annu. Rev. Entomol. 51:285-308.

Stephens, J.M. 2009. Bean, Yard-Long-Vigna unguiculata subsp. sesquipedalis (L.) Verde. Hort. Sci. Dep. Florida Coop. Exten. Serv., Inst. Of Food and Ag. Sci. 1pp.

Stern, V.M. 1969. Interplanting alfalfa in cotton to control lygus bugs and other insect pests. Proceedings Tall Timbers Conference on Ecological Animal Control by Habitat Management. 1:55-60.

Sutton, B.C. 1980. The Coelomycetes. Fungi Imperfecti with Pycnidia, Acervuli and Stromata. $\mathrm{CABI}, \mathrm{Kew}, \mathrm{UK}$.

Talekar, N.S. and Shelton, A.M. 1993. Biology, ecology, and management of the diamondback moth. Annu. Rev. Entomol. 38:275-301.

Tode, H.J., 1790. Fungi Mecklenbergensis Selecti 1:1-64. 
Tu, J.C., and Poysa, V. 1997. The diversity and overwintering of Colletotrichum coccodes in tomato fields in southwestern Ontario. Microbios 29:421-442.

Thurston, H.D., 1991. Sustainable Practices for Plant Disease Management in Traditional Farming Systems. Boulder CO: Westview. 279 pp.

United States Department of Agriculture's Agricultural Marketing Service. Fruit and Vegetable Division. Fresh Products Branch. 1997. United States standards for grades of fresh tomatoes: Effective October 1, 1991. Washington, D.C.: U.S. Dept. of Agriculture, Agricultural Marketing Service, Fruits and Vegetable Division, Fresh Products Branch

Voshell, R. J., Kotcon, J., Park, Y.L. and Rahman, M. 2014. Incidence of Colletotrichum coccodes in ripe tomato fruit after feeding by Brown Marmorated Stink Bug (Halyomorpha halys). Phytopathol. 104(Suppl. 3): S3.163.

Vichova, J., Stankova, B., and Pokorny, R. 2012. First report of Colletotrichum acuctatum on Tomato and Apple Fruits in the Czech Republic. Plant Dis. 96(5):769-770.

Wallingford, A.K., Kuhar, T.P., Pfeiffer, D.G., Tholl, D., Freeman, J., Doughty, H., and Schultz, P. 2013. Host plant preferences of Harlequin Bug (Hemiptera: Pentitomidae), and Evaluation of a Trap Cropping Strategy for its Control in Collard. J. Econ. Entomol. 106(1):283-288.

White, T. J., Bruns, T., Lee, S. J. W. T., \& Taylor, J. W. 1990. Amplification and direct sequencing of fungal ribosomal RNA genes for phylogenetics. PCR protocols: a guide to methods and applications, 18: 315-322.

Wiman, N.G. Walton, V.M., Shearer, P.W., Rondon, S.I., and Lee, J.C. 2015. Factors affecting flight capacity of brown marmorated stink bug, Halyomorpha halys (Hemiptera: Pentatomidae). J. Pest Sci. 88:37-47.

Winks, C., Adnersen, M., Charles, J., and Beever, R. 2014. Identification of Zeoliarus oppositus (Hemiptera: Cixiidae) as a Vector of 'Candidatus Phytoplasma australiense.' Plant Dis. 98(1):10-15.

Zalom, F.G., SmlLanick, J.M., and Ehler, L.E. 1997. Fruit damage by stink bugs (Hempitera: Pentatomidae) in bush-type tomatoes. J. of Econ. Entomol. 90(5)

Zinzhi, N. Toews, M.D., Buntin, D.G., Carpener, J.E., Huffaker, A., Schmelz, E.A., Cottrell, T., and Abdo, Z. 2014. Influence of brown stink bug feeding, planting date and sampling time on common smut infection of maize. Insect Sci. 21(5):564-571.

Zhu, G., Bu, W., Gao, Y., and Liu, G. 2012. Potential geographic distribution of brown marmorated stink bug invasion (Halyomorpha halys). PLoS One 7:1-10 


\section{Appendix}

ITS sequences of Colletotrichum isolate WV13 and isolates from H. halys leg and stylet.

'WV13' ITS sequence data GGAGGATCATTACTGAGTTACCGCTCTATAACCCTTTGTGAACGTACCTA ACCGTTGCTTCGGCGGGCAGGGGAAGCCTCTCGCGGGCCTCCCCTCCCGG CGCCGGCCCCCACCACGGGGACGGGGCGCCCGCCGGAGGAAACCAAACTC TATTTACACGACGTCTCTTCTGAGTGGCACAAGCAAATAATTAAAACTTT TAACAACGGATCTCTTGGTTCTGGCATCGATGAAGAACGCAGCGAAATGC GATAAGTAATGTGAATTGCAGAATTCAGTGAATCATCGAATCTTTGAACG CACATTGCGCTCGCCAGCATTCTGGCGAGCATGCCTGTTCGAGCGTCATT TCAACCCTCAAGCACCGCTTGGTTTTGGGGCCCCACGGCCGACGTGGGCC CTTAAAGGTAGTGGCGGACCCTCCCGGAGCCTCCTTTGCGTAGTAACTAA CGTCTCGCACTGGGATCCGGAGGGACTCTTGCCGTTAAACCCCCAAATTC TTTACAGGTTGACCTCGGATCAGGTAGGAATACCCGCTGAACTTAAGCAT ATCAATA

'WV 13' ITS sequence obtained from $H$. halys adult male stylet ATTACTGAGTTACCGCTCTATAACCCTTTGTGAACGTACCTAACCGTTGC TTCGGCGGGCAGGGGAAGCCTCTCGCGGGCCTCCCCTCCCGGCGCCGGCC CCCACCACGGGGACGGGGCGCCCGCCGGAGGAAACCAAACTCTATTTACA CGACGTCTCTTCTGAGTGGCACAAGCAAATAATTAAAACTTTTAACAACG GATCTCTTGGTTCTGGCATCGATGAAGAACGCAGCGAAATGCGATAAGTA ATGTGAATTGCAGAATTCAGTGAATCATCGAATCTTTGAACGCACATTGC GCTCGCCAGCATTCTGGCGAGCATGCCTGTTCGAGCGTCATTTCAACCCT CAAGCACCGCTTGGTTTTGGGGCCCCACGGCCGACGTGGGCCCTTAAAGG TAGTGGCGGACCCTCCCGGAGCCTCCTTTGCGTAGTAACTAACGTCTCGC ACTGGGATCCGGAGGGACTCTTGCCGTTAAACCCCCAAATTCTTTACAGG TTGACCTCGGATCAGGTAGGAATACCCGCTGAACTTAAGCATATCA

'WV 13' ITS sequence obtained from $H$. halys adult female leg ACGCGGAGGATCATTACTGAGTTACCGCTCTATAACCCTTTGTGAACGTA CCTAACCGTTGCTTCGGCGGGCAGGGGAAGCCTCTCGCGGGCCTCCCCTC CCGGCGCCGGCCCCCACCACGGGGACGGGGCGCCCGCCGGAGGAAACCAA ACTCTATTTACACGACGTCTCTTCTGAGTGGCACAAGCAAATAATTAAAA CTTTTAACAACGGATCTCTTGGTTCTGGCATCGATGAAGAACGCAGCGAA ATGCGATAAGTAATGTGAATTGCAGAATTCAGTGAATCATCGAATCTTTG AACGCACATTGCGCTCGCCAGCATTCTGGCGAGCATGCCTGTTCGAGCGT CATTTCAACCCTCAAGCACCGCTTGGTTTTGGGGCCCCACGGCCGACGTG GGCCCTTAAAGGTAGTGGCGGACCCTCCCGGAGCCTCCTTTGCGTAGTAA CTAACGTCTCGCACTGGGATCCGGAGGGACTCTTGCCGTTAAACCCCCAA ATTCTTTACAGGTTGACCTCGGATCAGGTAGGAATACCCGCTGAACTTAA GCATATC 